\title{
Asperity distribution and earthquake occurrence in the southern Kurile Islands arc
}

\author{
Susan Y. Schwartz and Larry J. Ruff \\ Department of Geological Sciences, The University of Michigan, Ann Arbor, MI 48109 (U.S.A.)
}

(Received June 5, 1986; revision accepted December 18, 1986)

\begin{abstract}
Schwartz, S.Y. and Ruff, L.J., 1987. Asperity distribution and earthquake occurrence in the southern Kurile Islands arc. Phys. Earth Planet. Inter., 49: 54-77.

The seismicity in the southern Kurile Islands arc is characterized by a complex overlapping of aftershock zones of a few great and many large earthquakes $\left(M_{s} \geqq 7.0\right)$. The spatial relationships of these aftershock zones can be explained in terms of a simple pattern of fault plane heterogeneity. The four largest earthquakes in this region are, from north to south, the 1963 Kurile Islands $\left(M_{\mathrm{w}}=8.5\right)$, the 1958 Etorofu $\left(M_{\mathrm{w}}=8.3\right)$, the 1969 Kurile Islands $\left(M_{\mathrm{w}}=8.2\right)$ and the 1973 Nemuro-Oki $\left(M_{\mathrm{w}}=7.8\right)$ events. Detailed body wave studies indicate that the moment release associated with each event is concentrated in a small portion of the aftershock area, with scale lengths $<100 \mathrm{~km}$. These regions of high moment release are the largest asperities. The areas that surround the large asperities slip in two modes: (1) coseismically during the great events; and (2) as distinct large $\left(M_{\mathrm{s}} \geqq 7.0\right)$ earthquakes both before and after the great events. The second mode involves either rupture of relatively weak regions which results in low-stress-drop events, or rupture of smaller asperities. The earthquakes produced by failure of small asperities tend to repeatedly rupture the same regions, and they have impulsive source time functions indicating rupture of highly stressed regions of the fault surface. By analysis of all $M_{\mathrm{s}} \geqq 7.0$ events since 1946 in this region we find a segmentation of the southern Kurile Islands thrust zone into strongly coupled regions with two scale lengths (dominant and secondary asperities) and weakly coupled regions (the surrounding areas generating the low-stress-drop events). The largest earthquakes and the smaller asperity earthquakes occur at the down-dip portion of the lithospheric interface, while the low-stress-drop events occur much closer to the trench axis. This implies a difference in the degree of mechanical coupling between the subducting and overriding plates, with the deeper portions having greater strength than the shallower parts.
\end{abstract}

\section{Introduction}

Many attempts to understand the subduction process have concentrated on only the largest earthquakes in subduction zones (e.g., Kanamori, 1977, 1981; Ruff and Kanamori, 1980; Lay et al., 1982). These events dominate seismic energy release and are therefore the most reliable indicators of stress regimes and plate motions. Studies of great earthquakes have revealed a large variation in seismicity among subduction zones that has been explained in terms of differing degrees of mechanical coupling between the subducting and overriding plates (Kelleher et al., 1974; Kanamori, 1977). Many physical properties of subduction zones have been suggested as contributing to the degree of mechanical coupling: the age of the subducting lithosphere, the plate convergence rate, the absolute velocity of the subducting and overriding plates, and the length, maximum depth and dip of the Benioff-Wadati zone (for discussion, see Uyeda and Kanamori, 1979; Ruff and Kanamori, 1980; Peterson and Seno, 1984; Jarrard, 1986).

Studies of the largest earthquakes in subduction zones have led to the concept of seismic gaps (Fedotov, 1965; Mogi, 1968; Sykes, 1971; Kelleher et al., 1973). The seismic gap hypothesis is based on the observation that rupture zones of great earthquakes tend to abut each other without sig- 
nificant overlap, with each zone experiencing earthquakes of a characteristic size with a more or less regular recurrence interval. The asperity model (Kanamori, 1981) has been proposed to explain the observations that underlie the seismic gap hypothesis. The asperity model is based on the observationally supported notion of fault plane heterogeneity, where a spectrum of mechanical strengths exists on the fault plane. This spectrum is idealized into two relevant end members, strong and weak. The strongest regions are referred to as asperities, and the model attributes the occurrence of the largest earthquakes to the failure of the largest asperities. The weak portions of the fault plane may slip with the large events with smaller displacements than at the asperities, or they may slip aseismically. The recurrence interval is the time necessary for the stress to rebuild to a level that exceeds the failure strength of the asperity. Physical properties of asperities are as yet not well known; however, conceptually they provide a good framework for understanding large earthquake occurrence.

With the successful application of the asperity model to interpret the rupture process of many of the largest subduction zone events (Lay and Kanamori, 1980; Beck and Ruff, 1984; Schwartz and Ruff, 1985), it now becomes important to integrate the occurrence of smaller magnitude events into our understanding of the subduction process. Locating the asperities which slip in great underthrusting earthquakes provides a primary image of fault plane heterogeneity in subduction zones. Our goal is to sharpen this image so that it better reflects true fault plane heterogeneity. This can be accomplished by examining the rupture process of the smaller magnitude earthquakes that occur adjacent to the largest events. These earthquakes contain information on the next smaller scale length of fault plane heterogeneity. This study investigates the nature of all $M_{\mathrm{s}} \geqq 7.0$ earthquakes that occurred in the southern Kurile Islands arc since 1946 in an attempt to obtain an integrated picture of earthquake occurrence in this subduction zone.

Four great earthquakes have occurred in the southern Kurile Islands arc in this century. They are from north to south, the 1963 Kurile Islands

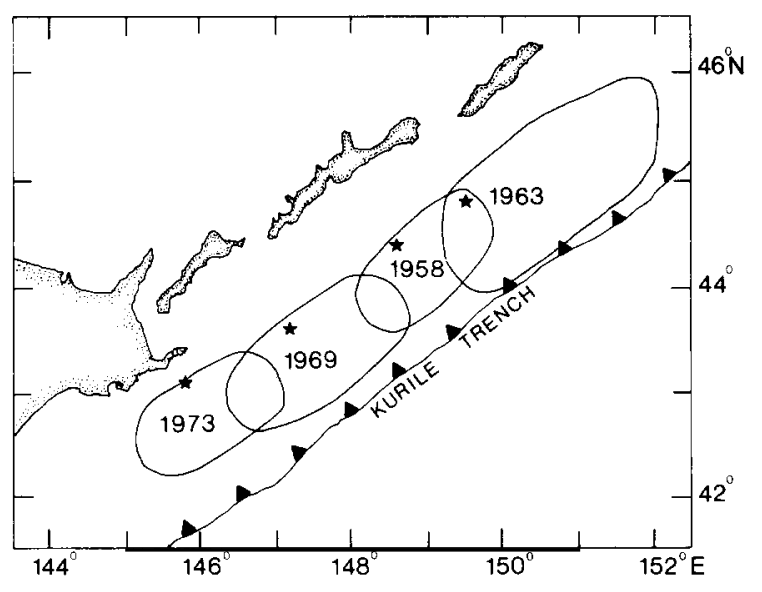

Fig. 1. Map of the southern Kurile Islands arc showing the three day aftershock areas of the four largest earthquakes. The epicenters are indicated by the solid stars.

$\left(M_{\mathrm{w}}=8.5\right)$, the 1958 Etorofu $\left(M_{\mathrm{w}}=8.3\right)$, the 1969 Kurile Islands $\left(M_{\mathrm{w}}=8.2\right)$ and the 1973 NemuroOki $\left(M_{\mathrm{w}}=7.8\right)$ earthquakes (Fig. 1). Detailed accounts of the rupture processes of the 1963 Kurile Islands (Beck and Ruff, 1987) and the 1969 Kurile Islands (Schwartz and Ruff, 1985) earthquakes have been published elsewhere and will be only briefly reviewed here. However, the details of the rupture of the other two great earthquakes along this trench must be determined before a regional perspective can be obtained. The first half of this paper will discuss the rupture process of these four great earthquakes. The second half will analyze the smaller magnitude events that overlap the rupture zones of the great earthquakes; and finally, we will present an integrated picture of subduction in the southern Kurile Islands arc.

\section{Data and method}

Twenty-five large $\left(M_{\mathrm{s}} \geqq 7.0\right)$ underthrusting earthquakes have occurred in the southern Kurile Islands trench $\left(42-46^{\circ} \mathrm{N}\right.$ and $145-152^{\circ} \mathrm{E}$, length of $800 \mathrm{~km}$ ) since 1946 . Table I lists the source parameters for these events. For the earthquakes that occurred since deployment of the World Wide Standardized Seismograph Network (WWSSN) 


\section{TABLE I}

\begin{tabular}{|c|c|c|c|c|c|c|c|}
\hline \multirow[t]{2}{*}{ No. } & \multirow[t]{2}{*}{ Date } & \multirow{2}{*}{$\begin{array}{l}\text { Origin time } \\
(\mathrm{h}: \mathrm{m}: \mathrm{s})\end{array}$} & \multicolumn{2}{|c|}{ Epicenter } & \multirow[t]{2}{*}{ Depth $(\mathrm{km})$} & \multirow{2}{*}{$\begin{array}{l}M_{\mathrm{s}} \\
\left(M_{\mathrm{w}}\right)^{\mathrm{a}}\end{array}$} & \multirow{2}{*}{$\begin{array}{l}\text { Focal mechanism } \\
\left(\text { st dip rake }^{\circ}\right)\end{array}$} \\
\hline & & & $\left({ }^{\circ} \mathrm{N}\right)$ & $\left({ }^{\circ} \mathrm{E}\right)$ & & & \\
\hline 1 & $12 / 21 / 46$ & $10: 18: 49$ & 44.1 & 148.2 & & 7.2 & \\
\hline 2 & $01 / 03 / 47$ & $02: 20: 33$ & 44.3 & 149.0 & 40 & 7.0 & \\
\hline 3 & $04 / 14 / 47$ & $07: 15: 29$ & 44.0 & 148.5 & & 7.0 & \\
\hline 4 & $09 / 10 / 48$ & $13: 48: 34$ & 43.5 & 147.0 & 40 & 7.1 & \\
\hline 5 & $11 / 06 / 58$ & $22: 58: 06$ & 44.4 & 148.6 & $0-30^{a}$ & $(8.3)^{a}$ & 2252090 \\
\hline 6 & $11 / 12 / 58$ & $20: 23: 29$ & 44.2 & 148.8 & 20 & 7.2 & $5^{b}$ \\
\hline 7 & $02 / 12 / 61$ & $21: 53: 43$ & 43.8 & 147.7 & 20 & 7.2 & $16^{b}$ \\
\hline 8 & $08 / 11 / 61$ & $15: 51: 34$ & 42.9 & 145.2 & 37 & 7.1 & $17^{b}$ \\
\hline 9 & $11 / 15 / 61$ & $07: 17: 06$ & 42.8 & 145.5 & 20 & 7.0 & $17^{b}$ \\
\hline 10 & $10 / 12 / 63$ & $11: 25: 55$ & 44.8 & 149.0 & $25^{\mathrm{a}}$ & 7.0 & 2253090 \\
\hline 11 & $10 / 13 / 63$ & $05: 17: 51$ & 44.8 & 149.5 & $0-30^{a}$ & $(8.5)$ & Kanamori 1970 \\
\hline 12 & $10 / 20 / 63$ & $00: 53: 11$ & 44.7 & 150.7 & $10^{a}$ & 7.2 & 2251590 \\
\hline 13 & $05 / 31 / 64$ & $00: 40: 36$ & 43.4 & 147.1 & $30^{a}$ & 7.2 & 2122090 \\
\hline 14 & $06 / 11 / 65$ & $03: 33: 46$ & 44.5 & 149.1 & 20 & 7.0 & 2302890 \\
\hline 15 & $01 / 29 / 68$ & $10: 19: 05$ & 43.5 & 146.7 & $35^{\mathrm{a}}$ & 7.2 & 2242090 \\
\hline 16 & $08 / 11 / 69$ & $21: 27: 41$ & 43.6 & 147.2 & $0-30^{\text {a }}$ & $(8.2)$ & Abe 1973 \\
\hline 17 & $06 / 17 / 73$ & $03: 55: 03$ & 43.1 & 145.8 & $5-30^{a}$ & $(7.8)$ & 23017109 \\
\hline 18 & $06 / 24 / 73$ & $02: 43: 23$ & 43.3 & 146.4 & $26^{\mathrm{a}}$ & 7.3 & 2051490 \\
\hline 19 & $06 / 10 / 75$ & $13: 47: 19$ & 43.0 & 147.7 & $3^{a}$ & 7.0 & 2270987 \\
\hline 20 & $01 / 21 / 76$ & $10: 05: 19$ & 44.7 & 149.2 & $20^{\mathrm{a}}$ & 7.0 & 2253090 \\
\hline 21 & $03 / 23 / 78$ & $00: 31: 04$ & 44.2 & 148.9 & 36 & 7.1 & \\
\hline 22 & $03 / 23 / 78$ & 03:15:09 & 44.1 & 149.3 & 28 & 7.5 & RK80 \\
\hline 23 & $03 / 24 / 78$ & $19: 47: 54$ & 44.1 & 148.6 & $0-30^{\mathrm{a}}$ & 7.6 & RK80 \\
\hline 24 & $02 / 23 / 80$ & $05: 51: 03$ & 43.5 & 146.8 & $34^{\mathrm{a}}$ & 7.1 & NK84 \\
\hline 25 & $03 / 24 / 84$ & $09: 44: 03$ & 44.1 & 148.2 & $31^{a}$ & 7.1 & PDE's \\
\hline
\end{tabular}

${ }^{a}$ Depths obtained from the literature or determined in this study and considered reliable. Other depths were taken from catalogues and considered less reliable.

${ }^{b}$ Focal mechanisms were assumed to be the same as listed event number. References are listed for focal mechanisms obtained from the literature RK80 is Regan and Kanamori (1980), NK84 is Nakanishi and Kanamori (1984).

instruments, our data consist of long-period vertical and horizontal component WWSSN P wave seismograms. Data for pre-WWSSN events consist of seismograms recorded by stations of the International Geophysical Year (IGY) and Canadian Seismograph Network (CSN) programs, and other available stations. Horizontal component $P$ wave seismograms were used when the vertical components were off-scale. Horizontal component receiver factors were determined by comparing the corresponding horizontal and vertical component wave amplitudes for the first few $\mathrm{P}$ wave cycles, or by using theoretical horizontal component receiver functions (Bullen, 1963) when the vertical component went off-scale immediately. Source time functions were obtained using the deconvolution technique of Ruff and Kanamori (1983), assuming a Green's function that incorporates the $\mathrm{pP}$ and
$\mathrm{SP}$ surface reflections and ocean layer multiple reflections. A distributed source or a point source was used depending on the size and approximate depth extent of the particular event. The source depths were taken from recent catalogues or determined by the method of Christensen and Ruff (1985), where the best depth concentrates the deconvolved moment release toward the beginning of the source time function. Focal mechanisms for these events were obtained from published values (see references in Table I) or from first-motions when published solutions were unavailable. The times of consistent features of the moment rate functions were measured from station to station and observable directivity of these features was used to determine their spatial location on the fault plane. This technique has been successfully applied in studies of the rupture processes of the 
1979 Colombia earthquake (Beck and Ruff, 1984), the 1976 Mindanao event (Beck and Ruff, 1985) and the 1968 Tokachi-Oki and the 1969 Kurile Islands events (Schwartz and Ruff, 1985).

\section{Rupture process of the four largest southern Kurile Islands events}

\subsection{Kurile Islands earthquake}

The October 13, 1963 Kurile Islands event ( $M_{\mathrm{w}}$ $=8.5$ ) occurred at the northeastern end of the southern Kurile Islands arc (Fig. 1). Its hypocentral parameters are listed in Table I. The focal mechanism determined by Kanamori (1970) indicates a pure dip-slip source with a fault strike of $\mathrm{N}$ $43^{\circ} \mathrm{E}$ and dip of $22^{\circ}$ to the northwest. Kanamori (1970) estimated the rupture length, direction and velocity by modeling the amplitude asymmetrices observed in the long-period Love and Rayleigh wave radiation patterns. He found a northeasterly rupture length of $250 \mathrm{~km}$, with an apparent rupture velocity of $3.5 \mathrm{~km} \mathrm{~s}^{-1}$. The parameters determined by Furumoto (1979) from the initial phase radiation pattern of long-period Rayleigh waves are in good agreement with those found by Kanamori (1970). Furumoto (1979) also determined the source duration of this event to be 97 $s$ based on the sum of the initial phases of longperiod Rayleigh waves radiated in opposite directions from the source $\left(R_{n}\right.$ and $\left.R_{n+1}\right)$.

Beck and Ruff (1987) have studied the longperiod $P$ waves from the 1963 Kurile Islands event to obtain the details of the rupture process. They deconvolved source time functions from $28 \mathrm{P}$ wave seismograms recorded at WWSSN stations. Source time functions and seismograms for two representative stations at opposite azimuths are shown in Fig. 2a. The seismograms are complex, which suggests a multiple shock character for this event. All of the source time functions have three pulses of moment release, each with a duration of 20-30 s. The total source duration obtained from the body waves is in agreement with the value determined by Furumoto (1979) from surface waves. Three features of the source time functions are consistent from station to station, and are marked with arrows in Fig. 2a. These features are the truncation of the first pulse (A), and the start (B) and truncation $(C)$ of the third pulse. Based on the relative timing of these features at different azimuths, the associated regions on the fault plane that slipped were located. Directivity associated with feature $A$ indicates that a $60 \mathrm{~km}$ region northeast of the epicenter slipped during the first $25 \mathrm{~s}$ of this event (Fig. 2b). Features B and C are well located and indicate that the third pulse of moment release originated between 190 and 245 $\mathrm{km}$ northeast of the epicenter (Fig. 2b). While the timing of the onset and the truncation of the second pulse is difficult to identify on the source time functions, a tomographic inversion for the moment rate function on a grid of $x-t$ values (Ruff, 1984) reveals a coherent event between 120 and $160 \mathrm{~km}$ northeast of the epicenter (Fig. 2b).

In summary, the 1963 Kurile Islands earthquake ruptured two well-resolved and one poorly resolved asperities with scale lengths of about 60 $\mathrm{km}$ each (Fig. 2b). The moment release associated with these three asperities amounts to less than one-half of the surface wave moment of $75 \times$ $10^{27}$ dyn cm determined by Kanamori (1970). Beck and Ruff (1987) propose that a long-period component of moment release over the entire aftershock area is necessary to reconcile this difference, indicating that areas of the fault plane surrounding the asperities slipped coseismically.

\subsection{Etorofu earthquake}

The subduction zone segment just southwest of the 1963 Kurile Islands source area ruptured in a great earthquake on November 6, $1958\left(M_{\mathrm{w}}=8.3\right)$. The focal mechanism of this event determined by P wave first-motions (Fukao and Furumoto, 1979) indicates that it is a shallow thrust event, consistent with solutions obtained for the other large earthquakes along the southern Kurile Islands trench. The epicenter of this event is located at the central down-dip edge of the aftershock area (Fig. 1). The aftershock area, based on the relocations of Kelleher et al. (1973), is smaller than the aftershock areas of the neighboring 1963 and 1969 Kurile Islands events. Fukao and Furumoto (1979) 
a)
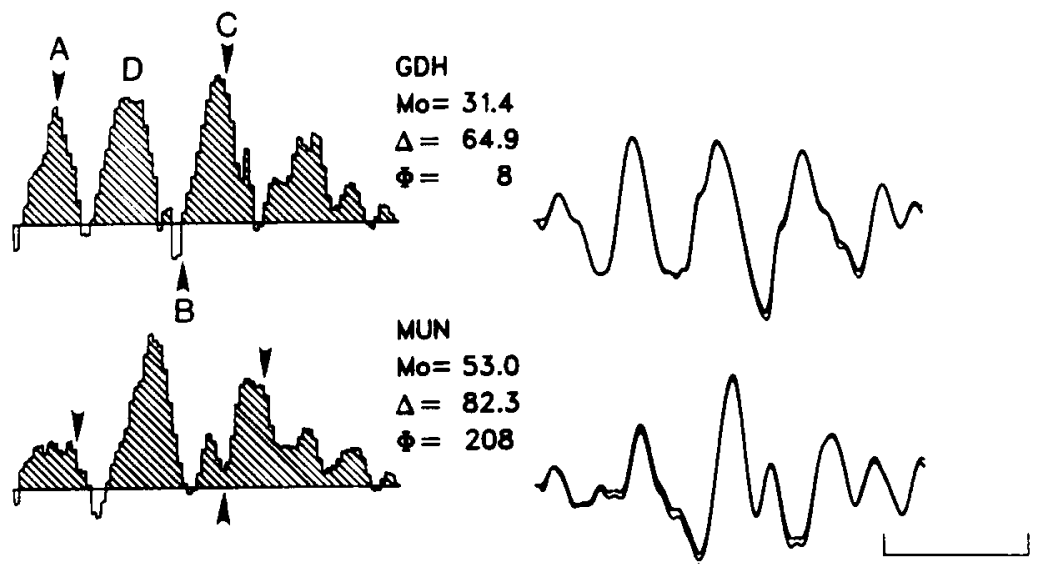

$60 \mathrm{sec}$

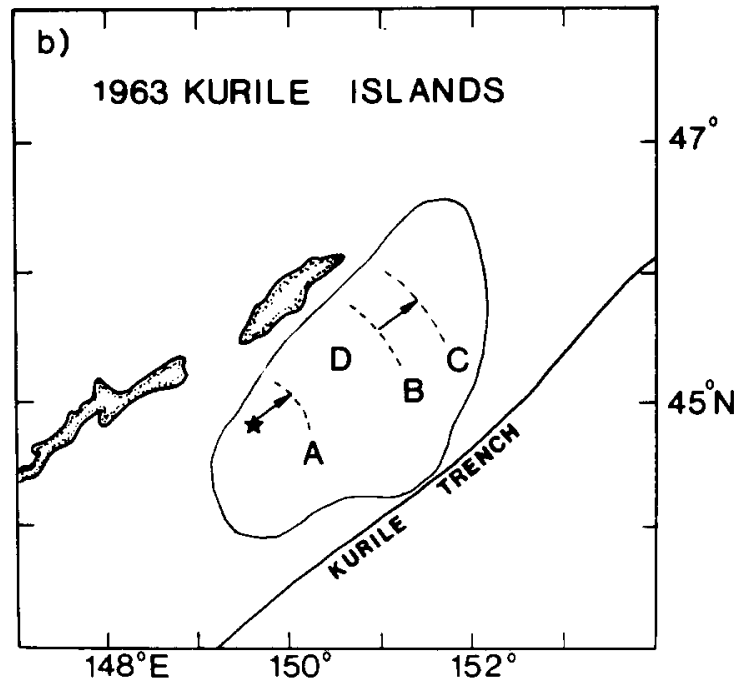

Fig. 2. (a) Deconvolved source time functions for the 13 October, 1963 Kurile Islands earthquake together with observed (solid trace) and synthetic (dashed trace) seismograms. Moments are in units of $10^{27}$ dyn $\mathrm{cm}$, distances and azimuths are in degrees. Arrows mark features used in the directivity study. (b) Map location of the features identified in the source time functions. The areas from the epicenter (star) to A, and from B to C represent well-located asperities, the second pulse of moment release locates between A and B in the region labeled $D$.

assumed a bilateral fault model with northeastsouthwest rupture directions, a rupture velocity of $3.5 \mathrm{~km} \mathrm{~s}^{-1}$ and a total fault length of $150 \mathrm{~km}$, and determined an average seismic moment of $44 \times$ $10^{27} \mathrm{dyn} \mathrm{cm}$. Their data were Love and Rayleigh waves recorded by the long-period Benioff and Press-Ewing seismographs. The large seismic moment and relatively small aftershock area result in a high stress drop for this event. The unusually large felt area reported for this earthquake seems to corroborate its high stress drop nature (Fukao and Furumoto, 1979). We studied both long-period $P$ waves and Love waves from the 1958 event to obtain the source characteristics.

3.2.1. $P$ waves. The 1958 Etorofu earthquake oc- 
TABLE II

1958 Etorofu earthquake

\begin{tabular}{|c|c|c|c|c|c|c|c|}
\hline STA & COMP & $\begin{array}{l}\mathrm{AZ} \\
\left({ }^{\circ}\right)\end{array}$ & $\begin{array}{l}\text { DIST } \\
\left({ }^{\circ}\right)\end{array}$ & $\begin{array}{l}T_{\mathrm{s}} \\
(\mathrm{s})\end{array}$ & $\begin{array}{l}T_{\mathrm{g}} \\
(\mathrm{s})\end{array}$ & $\begin{array}{l}M_{0} \\
\left(10^{27} \mathrm{dyn} \mathrm{cm}\right)\end{array}$ & $\begin{array}{l}T_{\mathrm{D}} \\
(\mathrm{s})\end{array}$ \\
\hline \multicolumn{8}{|c|}{$\mathrm{P}$ waves } \\
\hline HAL & E & 22.4 & 86.9 & 20 & 20 & 7.1 & \\
\hline OTT & $\mathrm{z}$ & 29.7 & 82.3 & 1 & 75 & 3.1 & \\
\hline PAS & $z$ & 62.3 & 69.1 & 1 & 90 & 19.0 & \\
\hline HUA & $\mathbf{Z}$ & 62.8 & 130.5 & 15 & 7 & & \\
\hline CAA & $\mathbf{N}$ & 172.6 & 117.1 & 15 & 50 & & \\
\hline PMT & $\mathbf{Z}$ & 265.1 & 129.6 & 15 & 75 & & \\
\hline LWI & $\mathbf{Z}$ & 290.4 & 112.5 & 15 & 75 & & \\
\hline UPP & $\bar{E}$ & 335.9 & 68.6 & 15 & 75 & & \\
\hline \multicolumn{8}{|c|}{ Love waves } \\
\hline \multirow[t]{2}{*}{ UPP } & $\mathrm{G} 2(\mathrm{~T})$ & 335.9 & 68.6 & 1 & 90 & 19.2 & 10 \\
\hline & $\mathrm{G} 3(\mathrm{~T})$ & & & 1 & 90 & 20.3 & 0 \\
\hline \multirow[t]{3}{*}{ PAS } & G2(N) & 62.3 & 69.1 & Strain & Strain & 73.2 & 80 \\
\hline & $\mathrm{G} 3(\mathrm{~N})$ & & & Strain & Strain & 48.3 & 100 \\
\hline & $\mathrm{G} 4(\mathrm{~T})$ & & & 30 & 90 & & 140 \\
\hline RVR & G2(E) & 61.9 & 69.7 & 1 & 90 & & 70 \\
\hline
\end{tabular}

$\mathrm{AZ}$ is the azimuth of the station relative to the event, DIST is the epicentral distance, $T_{\mathrm{s}}$ and $T_{\mathrm{g}}$ are the period of the seismometer and galvanometer, respectively, $M_{0}$ is the static seismic moment and $T_{\mathrm{D}}$ is the group delay relative to the synthetic.

curred before installation of WWSSN instruments making well-recorded body wave seismograms relatively scarce. We were able to obtain useful records from eight stations (Table II). However, instrument responses are well-known for only four of the stations. Seismograph phase responses were determined from the amplitude response assuming a minimum phase seismic system (Bolduc et al., 1972) for the E-W Sprengnether seismograph at Halifax and the long-period vertical Benioff seismograph at Ottawa (Hodgson, 1958). Both amplitude and phase responses were available for the vertical Sprengnether seismograph at Huancayo, Peru (Miller, 1963) and for the long-period Benioff seismograph at Pasadena. For the four remaining stations (Cape Adare, Antarctica; Pietermaritzburg, Africa; Lwiro, Africa and Uppsala, Sweden), where reliable response curves were unavailable, the instrument responses were calculated using Hagiwara's formula (Hagiwara, 1958). In all cases the periods of the seismometers and galvanometers were known; however, the magnification, damping and coupling parameters were estimated.

The $\mathrm{P}$ waves from all eight stations were deconvolved, resulting in the source time functions shown in Fig. 3. The moment determinations are given in Table II. A source Green's function uniformly distributed over a $0-30 \mathrm{~km}$ depth was used in the deconvolution process for each signal. However, other deconvolution parameters such as the damping, the signal time window, and the discretization of the source time functions, were allowed to vary between stations to accommodate the different instrument characteristics. The source time functions are remarkably similar from station to station considering the variety in instrumentation. They all consist of one dominant pulse of moment release which has a total duration of about $25 \mathrm{~s}$. Assuming a reasonable rupture velocity of $3 \mathrm{~km}$ $\mathrm{s}^{-1}$, this implies a rupture length of 75 or $150 \mathrm{~km}$ for unilateral and bilateral rupture, respectively. The three day aftershock area of this event is 150 $\mathrm{km}$ long and $70 \mathrm{~km}$ wide, so the 1958 event may have ruptured the entire aftershock area; however, we chose a conservative estimate of $100 \mathrm{~km}$ for the size of the region of concentrated slip.

Only those seismic moments obtained from stations for which the instrument response was known can be considered reliable (Table II). Of these four stations, Huancayo is located at a distance where the $\mathrm{P}$ waves are diffracted around the outer core 


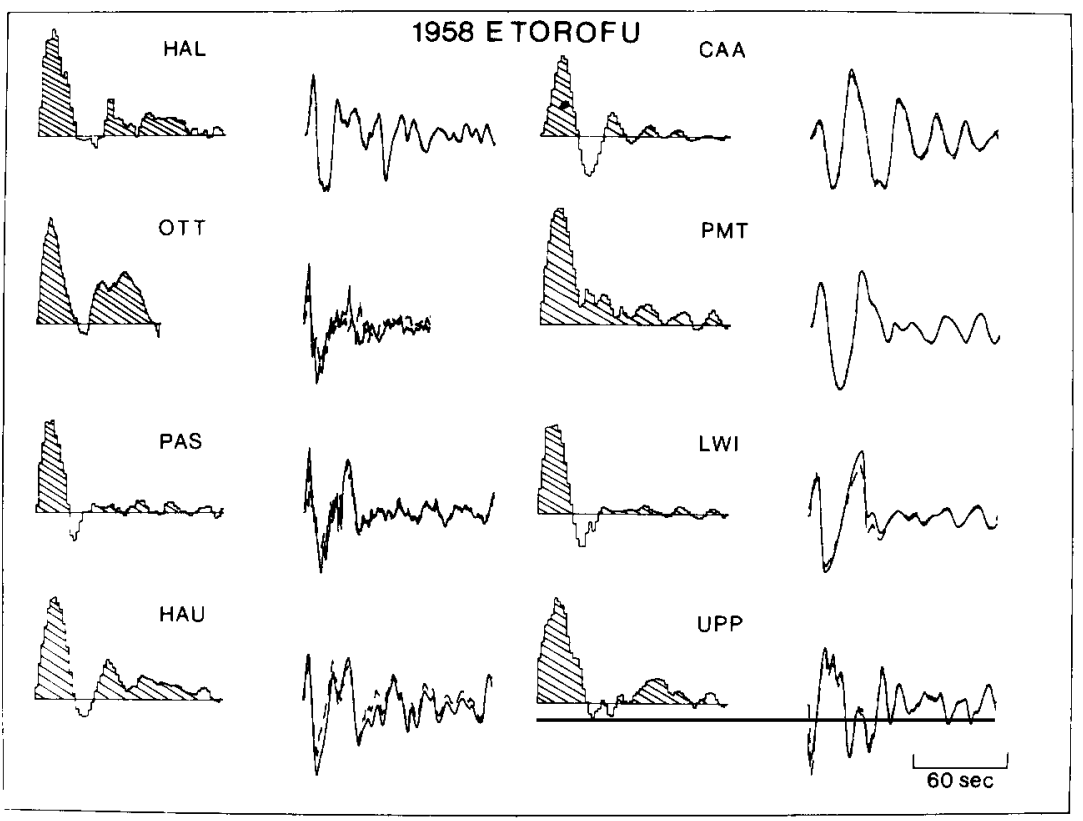

Fig. 3. Deconvolved source time functions for the 1958 Etorofu earthquake together with observed (solid trace) and synthetic (dashed trace) seismograms. Instrument characteristics, moment determinations, distances and azimuths to the stations are given in Table II.

resulting in diminished amplitudes for which geometric spreading corrections are quite uncertain. The seismic moments from the three reliable stations vary from $3 \times 10^{27}$ to $19 \times 10^{27}$ dyn $\mathrm{cm}$, giving an average of $10 \times 10^{27} \mathrm{dyn} \mathrm{cm}$. This value is only one-quarter of the surface wave moment found by Fukao and Furumoto (1979). Because the 1958 event occurred before deployment of WWSSN instruments, it is the only great earthquake we discuss for which the surface waves have not been extensively studied. To investigate the discrepancy between the body wave and surface wave moments, we analyzed surface waves from the Etorofu earthquake.

3.2.2. Surface waves. We obtained Love waves recorded on horizontal long-period Benioff seismographs at Uppsala, and on the $\mathrm{N}-\mathrm{S}$ component linear strain seismograph at Pasadena. The instrument characteristics for each station are listed in Table II.

The strain seismograph is a linear extensometer with a velocity transducer. Recording is accomplished by an overdamped $(h=4)$ galvanometer with a natural period of $180 \mathrm{~s}$. This instrument was calibrated in 1959 and ran with a static magnification of 18.3 for incident waves with a constant phase velocity of $5 \mathrm{~km} \mathrm{~s}^{-1}$. The directional response to transverse waves is proportional to $\left(\frac{1}{2} \sin 2 \theta\right)$, where $\theta$ is the incident angle of the waves at the station measured from north. Therefore the response of the strain seismograph remains the same when the wave direction is reversed.

The Love waves were windowed for group velocities between 3.9 and $4.6 \mathrm{~km} \mathrm{~s}^{-1}$, digitized and rotated to obtain transverse components in the case of the Benioff 1-90 seismographs. They were then band-pass filtered from 150-350 s using a phaseless three pole Butterworth filter. For comparison, synthetic seismograms were computed using the technique of Kanamori (1970) for a finite fault using the parameters determined by Fukao and Furumoto (1979), i.e. bilateral rupture of $75 \mathrm{~km}$ to the NE and SW at a rupture velocity of $3.5 \mathrm{~km} \mathrm{~s}^{-1}$. However, we used a focal mechanism with a $10^{\circ}$ shallower dip than that determined by Fukao and Furumoto (1979) to be 
consistent with a dilatational first motion recorded at Suva, Fiji. The synthetics were filtered in the same manner as the data. Cross-correlation of the synthetics with the data yielded moment and group delay estimates (Table II, Fig. 4).

Two of the phases modeled here (G2 and G3 from UPP) were also modeled by Fukao and Furumoto, however, they obtained seismic moments that were a factor of 2 larger than our values. The excitation of surface waves by a dipslip source is proportional to $\left(M_{0} \sin 2 \delta\right)$, where $\delta$ is the dip of the fault plane, so that for an observed amplitude the moment is proportional to $(1 / \sin 2 \delta)$. Thus, using the $30^{\circ}$ dip determined by Fukao and Furumoto (1979) would decrease our moment determination by a factor of 1.3 , enhancing the moment discrepancy between the two values. We believe that the discrepancy in the moment determinations for these two phases is largely due to the difference in data processing. The observed G2 and G3 Love waves contain abundant high frequency energy that contributes to larger unfiltered peak to peak amplitudes (as reported by Fukao and Furumoto (1979)) as compared with the amplitudes from the filtered data that we report here.

The large observed group delays (Table II) are not consistent with our assumed source model and we believe that they are propagation effects. G2 and G3 recorded at UPP have no group delays relative to the synthetics; however, these same phases recorded at PAS have group delays of 80 and $100 \mathrm{~s}$. We modeled the $\mathrm{G} 4$ phase from the 1958 event recorded at PAS on the Press-Ewing seismograph but do not report the seismic moment obtained from this record because of a lack of confidence in the magnification of the instrument. However, this phase does exhibit a very large apparent group delay of $140 \mathrm{~s}$, which we also interpret as a propagation effect. Progressive orbits of Love waves traveling between the Etorofu source region and PAS exhibit a systematic increase in the associated group delays. G4, which travels nearly the same path as G2 but includes an extra global orbit, has almost twice the group delay of the G2 phase. To ensure that these large group delays are due to propagation effects, we calculated the group delays for the G2 and G4

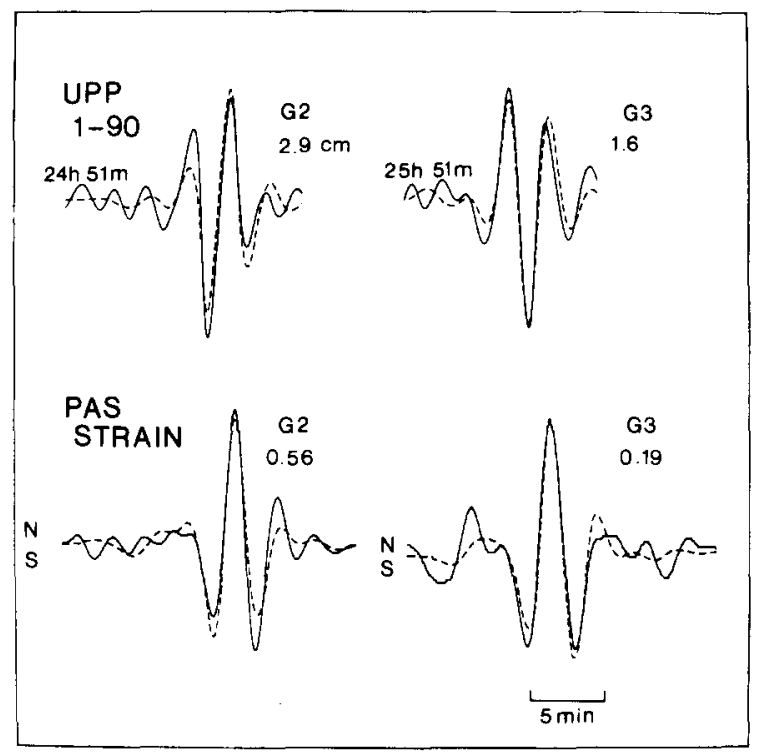

Fig. 4. Filtered observed (solid trace) and synthetic (dashed trace) Love wave seismograms from the November 6, 1958 Etorofu earthquake recorded at Pasadena (PAS) and Uppsala (UPP). Numbers indicate the peak to peak amplitudes of the observed traces.

waves at PAS for the 1969 Kurile Islands event. The proximity of these two events makes their propagation paths for long-period surface waves virtually identical. Similar size group delays were discovered at PAS for this event, confirming that they are due in part to propagation effects. Furumoto (1979) has previously identified the path between the Kurile Islands and western North and South America as being anomalous with respect to Rayleigh wave propagation.

The large group delays for long-period Love waves traveling between the 1958 Etorofu source region and PAS are indicative of strong lateral gradients in group velocity along this path which may cause focussing and defocussing of amplitudes, biasing moment determinations. To investigate this possibility, we computed the amplitude ratio of the filtered observed $\mathrm{G} 2 / \mathrm{G} 3$ phases recorded on the Pasadena strain seismograph and compared this with the filtered synthetic G2/G3 ratio. The observed ratio (2.9) differs from the predicted ratio (1.8), which suggests that amplitude asymmetries caused by focussing and defocussing effects are present at PAS. This 


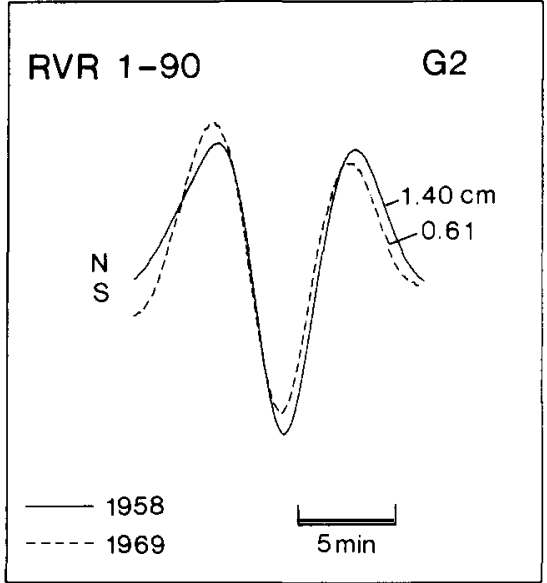

Fig. 5. Filtered observed Love wave seismograms from the 1958 Etorofu and the 1969 Kurile Islands earthquakes recorded at Riverside (RVR). The numbers are the peak to peak amplitudes. This comparison yields a seismic moment of $40 \times$ $10^{27}$ dyn $\mathrm{cm}$ for the 1958 event.

underscores the importance of a large data set in moment determinations.

The Benioff 1-90 seismograms from Riverside (RVR) were obtained for the 1958 Etorofu and the 1969 Kurile Islands events to directly compare Love wave amplitudes for these earthquakes. This comparison should allow a meaningful determination of the seismic moment for the 1958 event for the following reasons: these two events have similar focal mechanisms and source characteristics (the dip of the 1969 fault plane is $4^{\circ}$ shallower than the 1958 fault plane); their close proximity causes the propagation paths of long-period surface waves to be almost identical; the surface wave moment for the 1969 event is well determined (Abe, 1973); and the Benioff 1-90 instrument recording both events is stable and well calibrated. The direct comparison of G2 amplitudes recorded at RVR for both events (Fig. 5) yields a seismic moment for the 1958 event that is 2.2 times as large as the moment of the 1969 event $\left(22 \times 10^{27} \mathrm{dyn} \mathrm{cm}\right)$. The $4^{\circ}$ difference in dip between the two focal mechanisms predicts that for the same moment, the amplitude of the 1969 event should be 1.2 times larger than the 1958 event. Correcting for the focal mechanism difference, this comparison yields a seismic moment for the
1958 event of $40 \times 10^{27} \mathrm{dyn} \mathrm{cm}$. This value is consistent with the value reported by Fukao and Furumoto (1979). Considering all of the information available concerning the seismic moment of the 1958 Etorofu earthquake, our best estimate of the moment is $40 \pm 20 \times 10^{27} \mathrm{dyn} \mathrm{cm}$. In general, the trade-off between fault dip and seismic moment can produce significant uncertainties in the seismic moment given the typical uncertainties in focal mechanism. In addition, the large uncertainties regarding instrument responses that plague the pre-WWSSN era make precise seismic moment determinations for historical earthquakes difficult at best. Estimates of seismic moment based on a small sampling of seismic phases typically yields a range of values rather than a well determined mean; our study of the 1958 event is a case in point.

\subsection{Kurile Islands earthquake}

The August 11, 1969 Kurile Islands $\left(M_{\mathrm{w}}=8.2\right)$ earthquake occurred just southwest of the 1958 Etorofu event. The static seismic moment of $22 \times$ $10^{27} \mathrm{dyn} \mathrm{cm}$ and shallow thrust focal mechanism were determined by Abe (1973) on the basis of the radiation pattern of multiple long-period Love and Rayleigh waves. The $P$ waves were studied by Schwartz and Ruff (1985); we now summarize their results. P waves from 18 azimuthally well distributed WWSSN stations were deconvolved to obtain source time functions. Two of these time functions, together with the observed and synthetic seismograms, are shown in Fig. 6a. Both the seismograms and the source time functions resemble those obtained from the 1958 Etorofu event in their simplicity (see Figs. 3 and 6).

The 1969 Kurile Islands rupture commenced with a small foreshock $5 \mathrm{~s}$ before the main shock. The subsequent moment release is dominated by one pulse with a total duration of about $26 \mathrm{~s}$. Schwartz and Ruff (1985) identified the truncation of this pulse as a consistent feature of the moment release functions. The timing of this truncation (marked with arrows in Fig. 6a) shows clear directivity locating it about $40 \mathrm{~km}$ in a northeasterly (N $\left.60^{\circ} \mathrm{E}\right)$ direction from the epicenter, with a delay time of $17 \mathrm{~s}$ from the origin time. The area 

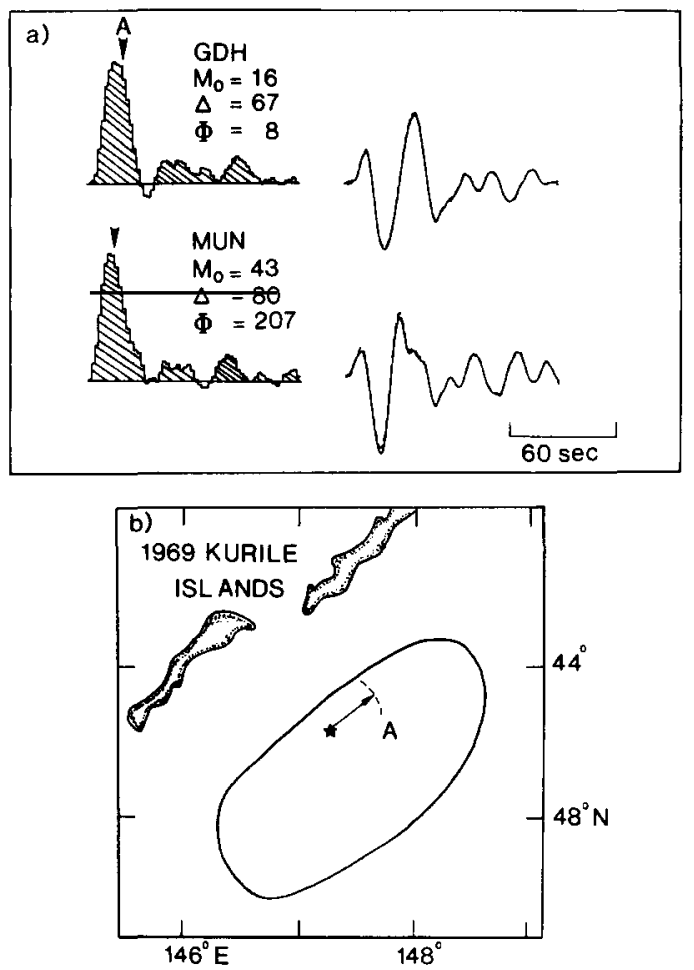

Fig. 6. (a) Deconvolved source time functions for the August 11, 1969 Kurile Islands earthquake together with observed (solid trace) and synthetic (dashed trace) seismograms. Moments are in units of $10^{27} \mathrm{dyn} \mathrm{cm}$, distances and azimuths are in degrees. The arrows (marked A) indicate the truncation of moment release, this feature is located using directivity. (b) Map location of event $A$. The region between the epicenter (star) and $\mathrm{A}$ is the asperity ruptured during this earthquake.

from the epicenter of the earthquake to this event constitutes the region of concentrated moment release thus identifying it as an asperity (Fig. 6b). An average seismic moment of $18 \times 10^{27} \mathrm{dyn} \mathrm{cm}$ is obtained from the body waves, which indicates that little moment release was produced by the surrounding region.

\subsection{Nemuro-Oki earthquake}

The southernmost of the four large Kurile Islands earthquakes occurred on June 17, 1973 off the eastern coast of Hokkaido (Fig. 1). The occurrence of this event was predicted on the basis of the seismic gap model; however, its magnitude $\left(M_{\mathrm{w}}=7.8\right)$ was much smaller than anticipated.
Shimazaki (1974) studied the $P$ wave first-motions and the radiation patterns and amplitudes of long-period surface waves to obtain a shallow dipping thrust mechanism (strike, $\phi=230$; dip, $\delta=27$; rake, $\lambda=113$ ) that is consistent with subduction of the Pacific plate beneath the Kurile Islands arc. Through comparison of the observed surface waves with synthetics, Shimazaki (1974) determined an average seismic moment of $6.7 \times$ $10^{27} \mathrm{dyn} \mathrm{cm}$ for this event.

The $P$ waves from several stations are shown in Fig. 7 with the station locations indicated on the focal sphere. GDH and KOD are characteristic of most of the seismograms; they start with relatively small amplitudes, build to a large peak amplitude at about $40 \mathrm{~s}$ and then fall of again. Stations AFI and KIP, which are located close to a $P$ wave radiation node for the focal mechanism published by Shimazaki (1974), have a ringing appearance to the seismograms (Fig. 7). This behavior is characteristic of nodal $\mathbf{P}$ waves from great earthquakes and may be due to moment release off the main fault, which is usually small except when recorded at stations that lie in nodal directions with respect to the main $P$ wave radiation. Other explanations for this behavior may be slight deviations from the first-motion or average focal mechanism during faulting, or the effect of later relatively small reflections and reverberations near the source that begin to dominate the seismograms over the direct arrival at stations in nodal directions. Regardless of the actual cause of the excessive ringing in the $P$ waves recorded at the nodal stations, it is not accounted for in the Green's functions, which results in oscillations in the deconvolved source time functions. Although TUC, COR, RIV and ADE are not located close to the nodal planes for the focal mechanism of Shimazaki (1974) (solid lines in Fig. 7), their $P$ wave seismograms resemble those recorded at the nodal stations AFI and KIP (Fig. 7) suggesting that a focal mechanism slightly different from Shimazaki's (1974) is appropriate (dashed lines in Fig. 7).

We have deconvolved the source time functions from long-period $\mathbf{P}$ waves from 18 WWSSN stations using a Green's function computed with our modified focal mechanism (strike, $\phi=230$; dip, $\delta=17$; rake, $\lambda=109$ ) and a source distributed 


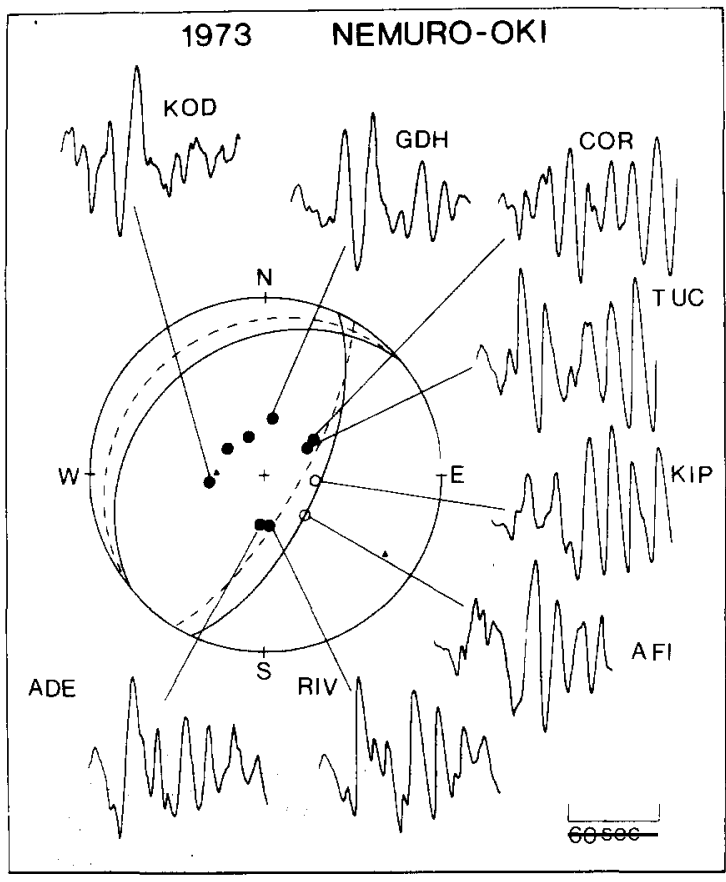

Fig. 7. Focal mechanism and observed seismograms from the June 17, 1973 Nemuro-Oki earthquake. The solid circles on this lower hemisphere projection are compressional first-motions. The solid lines are the nodal planes of Shimazaki (1974), the dashed lines are our preferred nodal planes.

between 5 and $30 \mathrm{~km}$. The results are shown in Figs. 8 and 9, station parameters are listed in Table III. The seismic moments obtained from the near nodal stations are higher than moments obtained from the other stations (Table III). This is caused by the relatively high amplitudes later in the seismograms that are still not modeled in the Green's functions, resulting in high moment release after the first major pulse. If we exclude these six stations (COR, TUC, AFI, KIP, ADE and RIV), we obtain an average seismic moment of $10 \times 10^{27} \mathrm{dyn} \mathrm{cm}$, a value slightly larger than the surface wave moment. Averaging the seismic moments in the main pulses only, gives a value of $6.4 \times 10^{27}$ dyn $\mathrm{cm}$ which is close to the surface wave moment.

The complexity of the source time functions in Figs. 8 and 9 makes a directivity analysis such as that applied to the 1969 Kurile Islands earthquake difficult. The only feature of the source time functions that can be clearly identified at all azimuths is the termination of the main pulse of moment release. This feature is indicated with arrows in Figs. 8 and 9. AFI has been excluded from the location scheme due to an ambiguity in choosing the start time on this record. The truncation event occurred at about $33 \mathrm{~s}$ and is located $100 \mathrm{~km}$ from the epicenter in a southeasterly (S $30^{\circ} \mathrm{E}$ ) direction (Fig. 10). The source time functions consist of a bifurcated pulse of moment release with a $40 \mathrm{~s}$ duration which appears to merge into a single pulse when observed at stations to the west and southwest (Figs. 8 and 9). This complexity argues against a smooth southeasterly rupture from the epicenter to the truncation event and may indicate the occurrence of subevents in the 1973 aftershock area. To further investigate this, we attempted a directivity analysis on the centroid time of the source time functions. Had the rupture propagated smoothly from the epicenter $100 \mathrm{~km}$ to the southeast, the centroid time would locate half way along the rupture trajectory. Instead, relatively weak directivity associated with the centroid time of the moment release locates it about $50 \mathrm{~km}$ from the epicenter in an easterly ( $\left.100^{\circ} \mathrm{E}\right)$ direction at a time of $20 \mathrm{~s}$. Using an iterative deconvolution technique, Kikuchi and Fukao (1987) identify two sub-events at 15 and $25 \mathrm{~s}$ about 45 and $70 \mathrm{~km}$ from the epicenter in easterly and southerly directions, respectively. These events correspond roughly to our centroid time and truncation events. It therefore appears that with the exception of a large sub-event at the southeastern edge of the aftershock area, that most of the moment release is concentrated within a semi-circular area about the epicenter with a $50 \mathrm{~km}$ radius.

\subsection{Dominant asperity distribution}

Our studies of the rupture processes of the four largest Kurile Islands earthquakes of this century provide a map of the dominant asperity distribution in this region (Fig. 11). This is our first image of the fault plane heterogeneity in the southern Kurile Islands subduction zone, with the asperities representing regions of enhanced strength. Exact asperity sizes are uncertain due to poor resolution of both asperity width and length. For the 1963 and 1969 Kurile Islands events, where directivity 


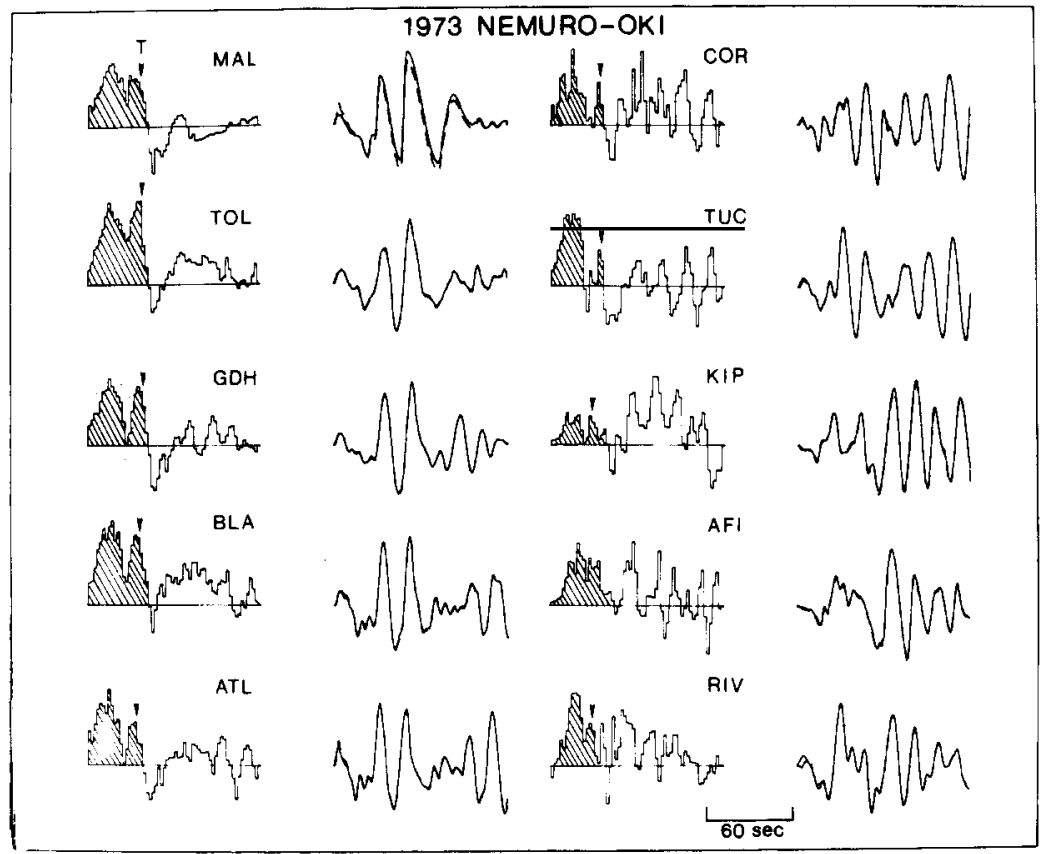

Fig. 8. Deconvolved source time functions for the 1973 Nemuro-Oki earthquake with observed (solid trace) and synthetic (dashed trace) seismograms. The Green's function was computed for our preferred focal mechanism. Arrows (marked T) indicate the location of the feature used in the directivity study. The distance and azimuth to the stations and the seismic moments are listed in Table III.

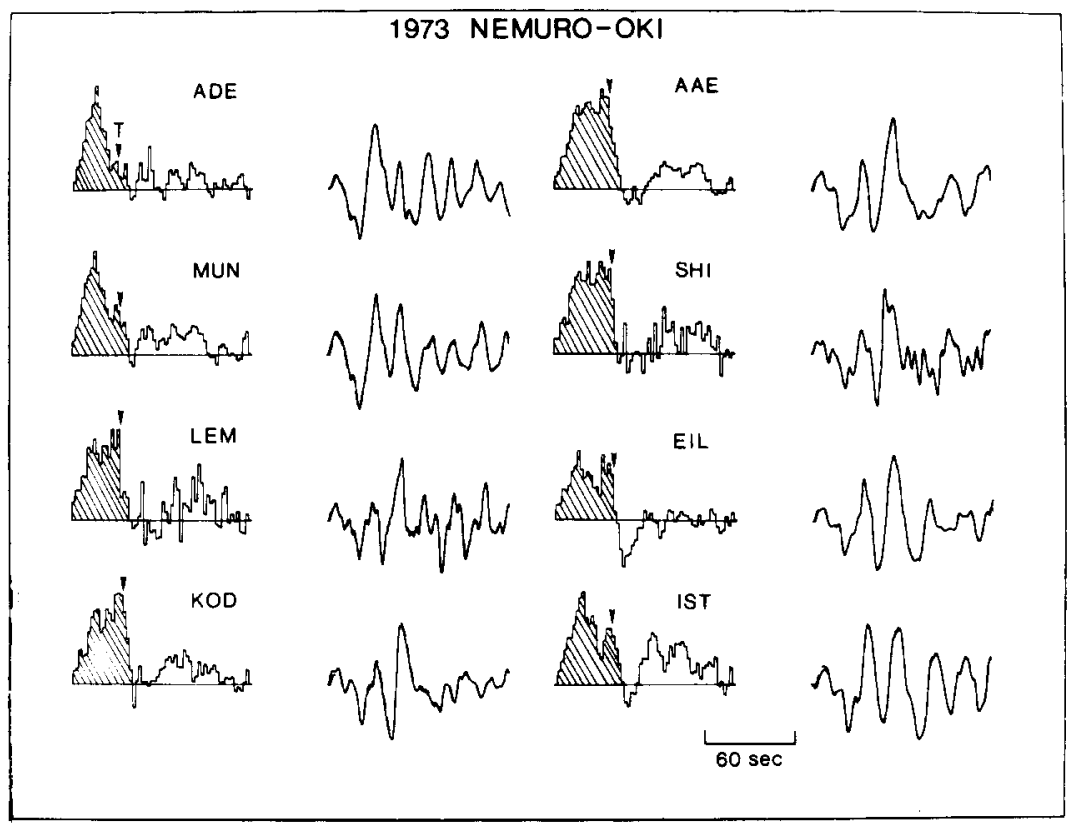

Fig. 9. See Fig. 8. 
TABLE III

1973 Nemuro-Oki earthquake

\begin{tabular}{|c|c|c|c|c|c|c|c|}
\hline STA & COMP & $A Z\left({ }^{\circ}\right)$ & $\operatorname{DIST}\left({ }^{\circ}\right)$ & $\operatorname{BAZ}\left({ }^{\circ}\right)$ & OBS CF & TH CF & $M_{0}$ \\
\hline$\overline{\mathrm{MAL}}$ & $\mathrm{z}$ & 336.3 & 96.1 & 21.5 & & & 2.7 \\
\hline TOL & $\mathbf{N}$ & 337.2 & 93.0 & 21.7 & & 0.37 & 6.6 \\
\hline GDH & $\mathbf{N}$ & 7.3 & 67.1 & 344.8 & 0.49 & 0.38 & 6.5 \\
\hline BLA & $\mathbf{N}$ & 35.2 & 89.7 & 328.1 & & 0.24 & 17.3 \\
\hline ATL & $\mathbf{E}$ & 39.9 & 91.2 & 325.8 & 0.25 & 0.16 & 6.0 \\
\hline COR & $\mathbf{N}$ & 53.9 & 62.1 & 394.0 & 0.26 & 0.23 & 22.1 \\
\hline TUC & $\mathbf{N}$ & 57.5 & 77.4 & 313.1 & 0.23 & 0.23 & 8.4 \\
\hline KIP & $\mathbf{N}$ & 96.3 & 51.2 & 308.6 & 0.28 & 0.30 & 33.0 \\
\hline AFI & $\mathbf{N}$ & 135.3 & 68.7 & 327.9 & 0.44 & 0.32 & 12.9 \\
\hline RIV & $\mathbf{N}$ & 175.4 & 76.7 & 355.9 & & 0.34 & 20.6 \\
\hline ADE & $\mathrm{N}$ & 185.9 & 77.9 & 5.3 & 0.55 & 0.27 & 15.3 \\
\hline MUN & $\mathbf{N}$ & 205.2 & 79.4 & 21.6 & 0.27 & 0.31 & 24.3 \\
\hline LEM & $\mathbf{N}$ & 224.8 & 60.5 & 31.3 & & 0.36 & 7.8 \\
\hline KOD & $\mathbf{N}$ & 262.6 & 67.2 & 47.6 & & 0.26 & 9.3 \\
\hline AAE & $\mathbf{E}$ & 288.2 & 96.1 & 44.8 & 0.31 & 0.19 & 6.5 \\
\hline SHI & $N$ & 294.4 & 72.6 & 50.1 & & 0.23 & 13.9 \\
\hline EIL & $\mathbf{N}$ & 305.0 & 83.9 & 43.6 & & 0.20 & 6.5 \\
\hline IST & $\mathbf{E}$ & 316.5 & 78.7 & 41.9 & & 0.33 & 12.9 \\
\hline
\end{tabular}

DIST is the epicentral distance, $\mathrm{AZ}$ and BAZ are the azimuth and back azimuth of the station relative to the event, OBS CF and TH $\mathrm{CF}$ are the correction factors derived from observed horizontal/vertical amplitudes and theoretically from Bullen (1963), respectively. $M_{0}$ is the static seismic moment in units of $10^{27} \mathrm{dyn} \mathrm{cm}$.

analyses were possible, asperity lengths are better determined. Therefore the asperity areas represented in Fig. 11 are conservative estimates. The asperities occupy one-quarter to one-half of the area of the coupled trench segment. Many large $\left(M_{\mathrm{s}} \geqq 7.0\right)$ earthquakes occur in the inter-asperity

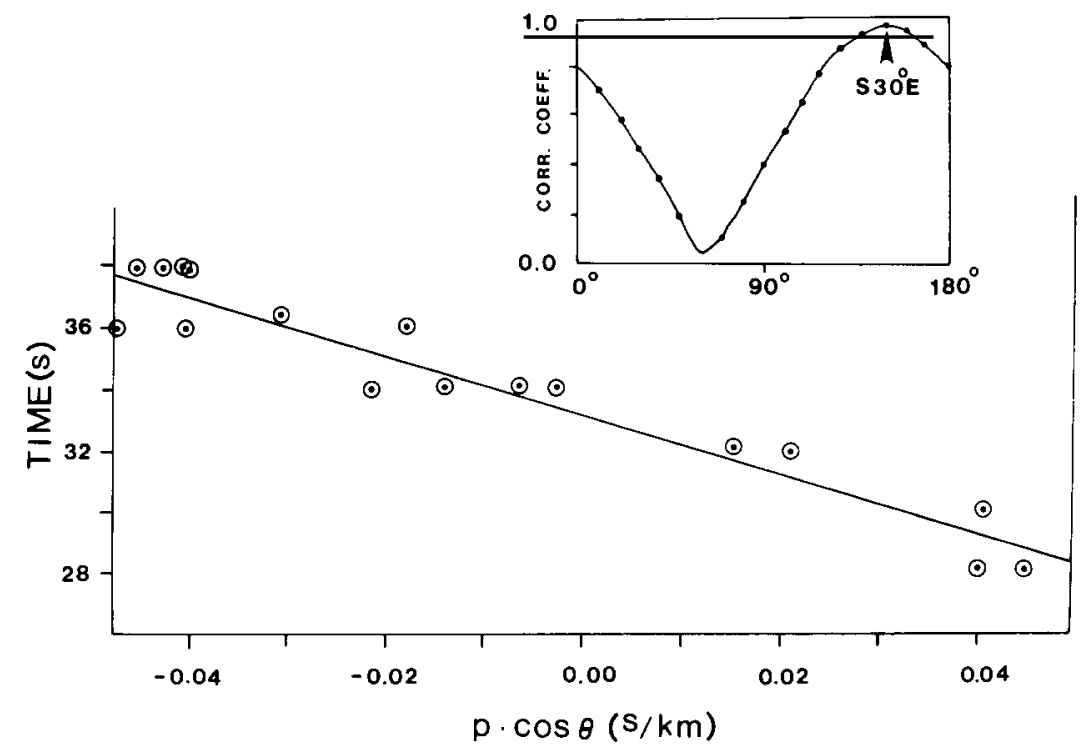

Fig. 10. Directivity of event $\mathrm{T}$ for the 1973 Nemuro-Oki earthquake. The delay time is plotted vs. the directivity parameter at each station. The best rupture azimuth from the epicenter is $\mathrm{S} 30^{\circ} \mathrm{E}$, the distance and delay time are $100 \mathrm{~km}$ and $33 \mathrm{~s}$, respectively. The inset shows the correlation coefficient as a function of the assumed rupture azimuth. 


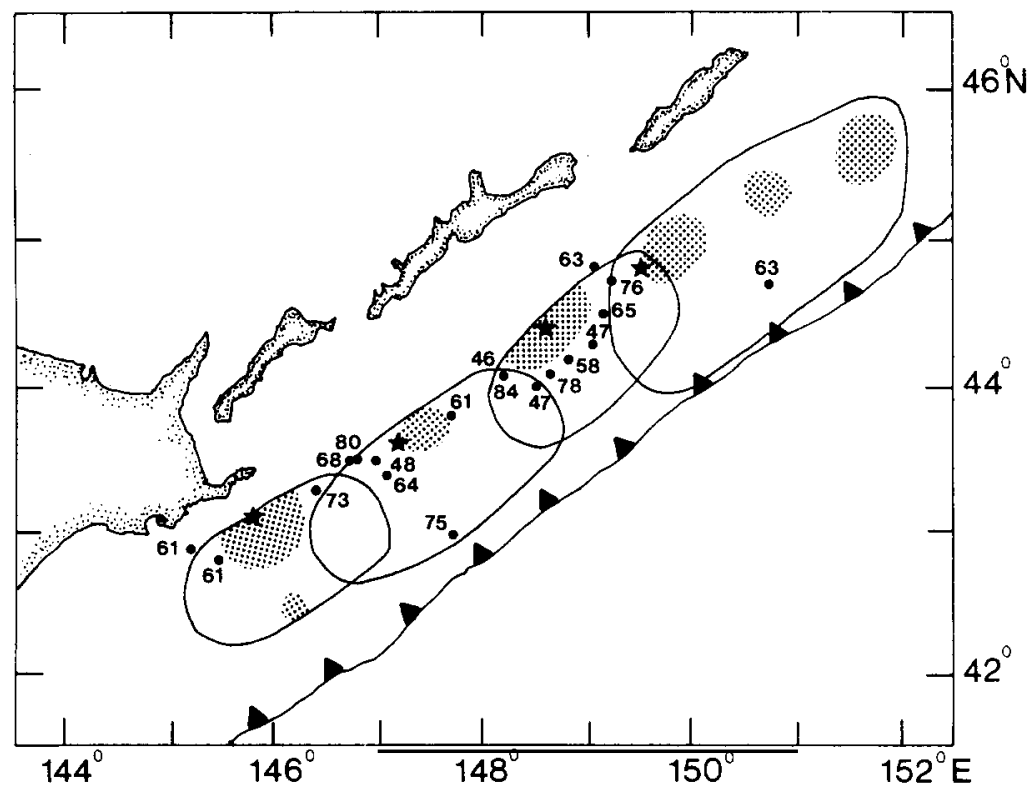

Fig. 11. Map of asperities (stippled region) ruptured during the four largest earthquakes in the southern Kurile Islands arc. The stars indicate the location of the mainshock epicenters. The solid circles and adjacent numbers indicate the locations and years of all $M_{\mathrm{s}} \geqq 7$ earthquakes that occurred in this region since 1946. Note that the locations of most of these events as well as the mainshock asperities are within the down-dip half of the aftershock areas.

regions (Fig. 11). Two interesting observations can be made from Fig. 11. The aftershock areas of the four great southern Kurile Islands earthquakes seem to be limited in size by the proximity of the adjacent earthquake asperities, i.e. the aftershock areas abut but do not significantly overlap adjacent earthquake asperities. With few exceptions, the earthquake asperity regions, as well as most of the $M_{s} \geqq 7$ earthquakes are located within the down-dip half of the aftershock areas. We will interpret this as a segregation of the plate interface into a strongly coupled zone (the down-dip half) and a weakly coupled zone (the up-dip half) based on the nature of the inter-asperity seismicity. The large inter-asperity earthquakes are of two types, characterized by either complex $P$ wave seismograms, long source durations and large aftershock areas (here termed low-stress-drop events), or impulsive $P$ wave seismograms and short source durations (termed impulsive events). In the next sections, the two classes of inter-asperity earthquakes will be considered separately and our final model of fault plane heterogeneity that integrates their occurrence with the great earthquakes will be presented.

\section{Low-stress-drop earthquakes in the southern Kurile Islands arc}

The occurrence of low-stress-drop events at oceanic trenches has been recognized for almost 60 years based on the low frequency content and long duration of some seismic waveforms (Wadati, 1928). Kanamori (1972) identified some of these events as 'tsunami earthquakes' due to their large tsunamis and relatively weak seismic radiation. He attributed the lack of high frequency waves and the strong tsunami excitation to a slow faulting process accompanied by large sea bottom deformation. The 1896 Sanriku earthquake, the 1946 Aleutian Islands earthquake and the June 10, 1975 Shikotan-Oki earthquake are examples of 'tsunami earthquakes' identified by Kanamori (1972, 1977). Fukao (1979) discussed the mechanism of 'tsunami earthquakes' using two events in the 
southern Kurile Islands arc (the Shikotan-Oki event on $6 / 10 / 75$ and the largest aftershock of the 1963 Kurile Islands earthquake on 10/20/63) as examples. Both of these events were preceded by great earthquakes, which occurred 6 years and 1 week earlier (the 1969 and 1963 Kurile Islands earthquakes, respectively). Fukao (1979) suggested that the two 'tsunami earthquakes' represent the upward and seaward extension of the rupture zone of the great earthquake predecessors into the sedimentary wedge. Fukao (1979) also suggested that this wedge of easily deformable sediments would yield slowly unless loaded suddenly by the occurrence of a great earthquake, thus emphasizing the importance of the timing of the 'tsunami earthquakes' relative to the previous great events. Many other authors have cited the October 20,1963 and the June 10,1975 events as anomalous with respect to their low frequency content and tsunami excitation (e.g. Shimazaki and Geller, 1977; Takemura et al., 1977; Utsu, 1980; Abe, 1981; Hatori, 1982). Utsu (1980) performed a systematic survey of 800 shallow earthquakes with $M \geqq 6.0$ in and around Japan. He characterized these earthquakes as normal, low frequency and very low frequency events, based on the relationship between the size of their felt area and their magnitude. He too found a relationship between the occurrence of great events and the distribution of low frequency events in space and time, noting that the low frequency events generally follow the occurrence of great earthquakes.

We have conducted our own survey of all earthquakes with $M_{\mathrm{s}} \geqq 7.0$ in the southern Kurile Islands and have identified three low-stress-drop events based on their anomalously long source process times (determined from the source time functions), and large aftershock areas, for earthquakes of their magnitude. These three events occurred on October 20, 1963, June 10, 1975 (both events have been previously recognized as anomalous) and June 11, 1965. Their hypocentral parameters are listed in Table $I$. The focal mechanisms for the 1963, 1975 and 1965 events have been slightly modified from those published by Fukao (1979), Shimazaki and Geller (1977) and Veith (1974), respectively, in order to remain consistent with observed first-motions. The aftershock areas and source time functions averaged from several stations are shown for each of the three events in Fig. 12.

To interpret the significance of the long source duration of the low-stress-drop events, we compare both the seismograms and source time functions of the three events with those of comparable magnitude impulsive earthquakes occurring near the same locations. Figure 13 shows this comparison with the time functions and seismograms for the low-stress-drop events above those from the impulsive earthquakes. The epicenters of the impulsive earthquakes are shown on Fig. 12. The $P$ wave seismograms for the low-stress-drop events are much more complicated than the seismograms from the other events. The source duration of the impulsive events is always $<16 \mathrm{~s}$, which is about the value expected for magnitude 7 events according to the scaling relations of Kanamori and
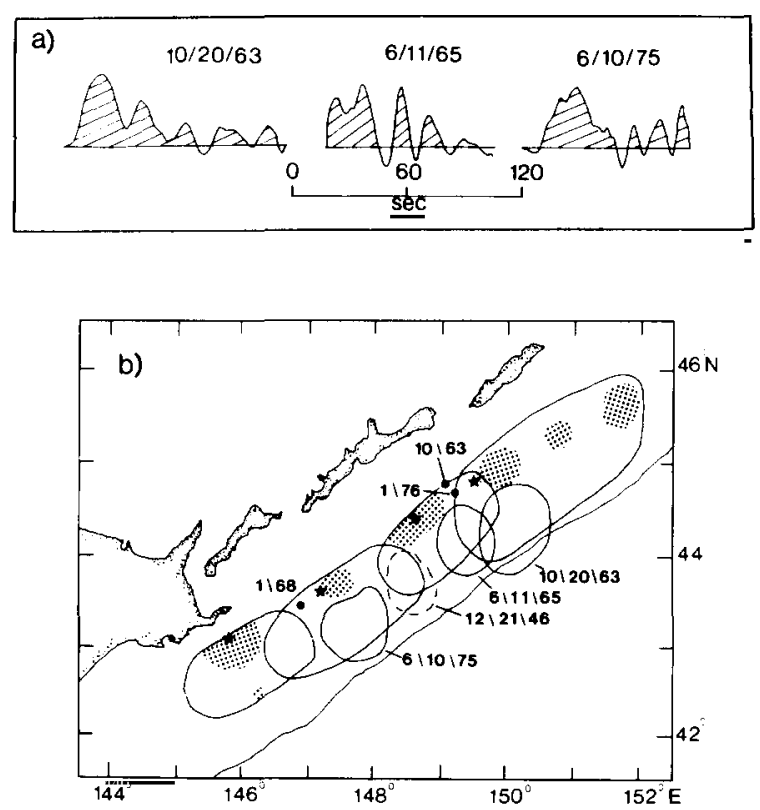

Fig. 12. (a) Deconvolved source time functions averaged from several stations for three of the low-stress-drop events. (b) Map of mainshock asperities (stippled regions) with 1 week aftershock areas of the four low-stress-drop events. The stars represent the mainshock epicenters and the solid circles indicate the location of three $M_{\mathrm{s}} \geqq 7$ events whose seismograms and source time functions are compared with the low-stressdrop events in Fig. 13. 


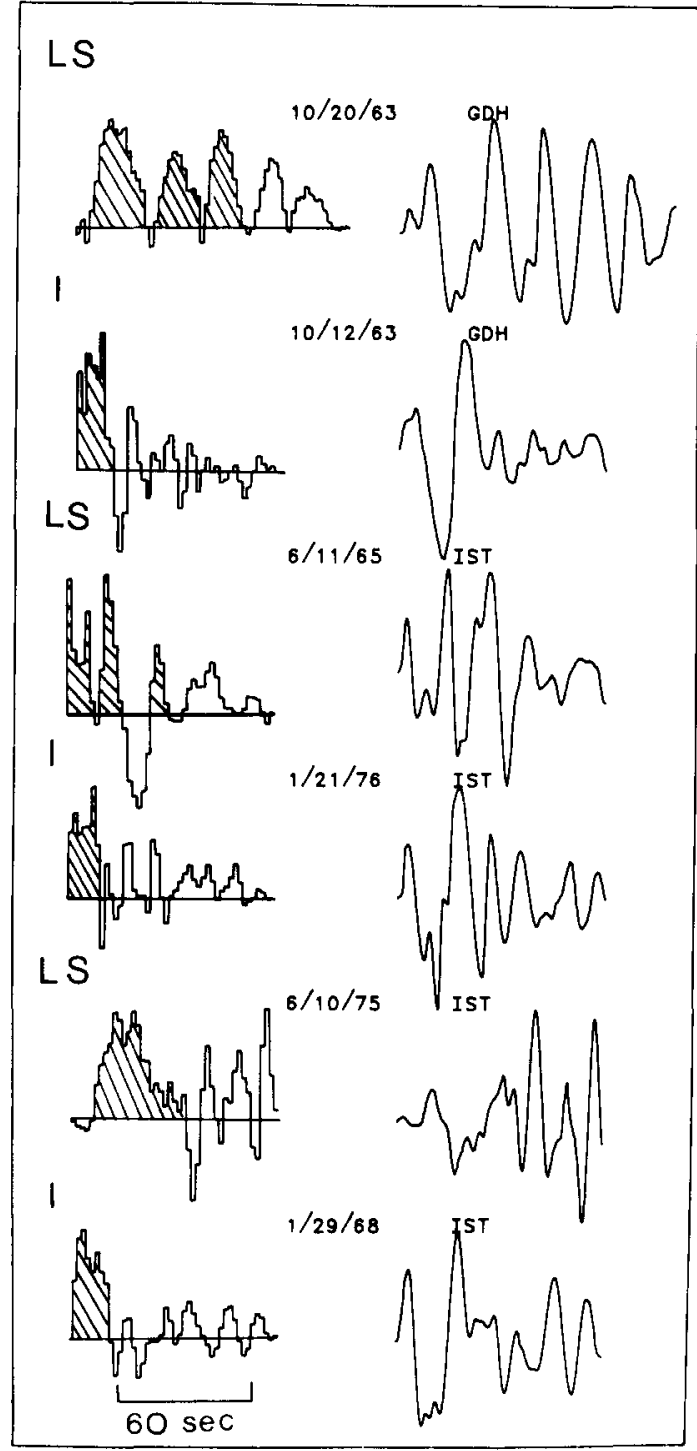

Fig. 13. Comparison of source time functions and seismograms from the low-stress-drop events (LS) with impulsive (I) earthquakes of comparable magnitude. The locations of the impulsive events are indicated in Fig. 12. Note the complexity of the low-stress-drop event seismograms compared with the impulsive event seismograms.

Anderson (1975). However, the low-stress-drop events have source durations on the order of $40 \mathrm{~s}$. On the basis of this comparison, as well as the timing of the low-stress-drop events within seven years of a great earthquake, we believe that their occurrence represents the rupture of weak regions of the lithospheric interface that have yielded seismically due to sudden loading by great earthquake predecessors.

The seismograms from the October 20, 1963 earthquake (Fig. 13) become periodic with a period of about $20 \mathrm{~s}$ at $35 \mathrm{~s}$ after initiation. This periodicity may be due to ocean layer multiple reflections. Beck and Ruff (1987) have modeled these reverberations as ocean layer bounces and found that they could match the seismograms with simpler source time functions if this event is located at a shallow depth $(\approx 3 \mathrm{~km})$, within low velocity material overlain by $5 \mathrm{~km}$ of water, and if the dip of the fault plane steepens during the rupture process. This interpretation is consistent with Fukao's (1979) suggestion that this event began as a shallow thrust event that extended upward into the accretionary wedge. If the latter pulses in the seismograms for the October 20, 1963 event are due to reverberations rather than source complexity, the resulting source time functions have durations of about $35 \mathrm{~s}$ rather than over $50 \mathrm{~s}$. Even with the shorter source duration, we believe this 'tsunami earthquake' represents the rupture of a weak region of the lithospheric interface. This conclusion also applies to the 1965 and 1975 events.

Utsu (1980) classified the December 21, 1946 earthquake (Table I) as a very low frequency event. We have plotted its approximate aftershock area based on the ISS locations in Fig. 12. Although only a few aftershocks within 1 week after the main event were listed, their large spatial distribution suggests that this event may meet our criteria for low-stress-drop events. Unfortunately, no seismograms could be acquired for this earthquake, so its nature remains speculative.

The spatial segregation of the rupture zones of the low-stress-drop events trenchward of the main shock asperities is quite clear in Fig. 12. Fukao and Kanjo (1980) discovered a similar well-defined zone of smaller magnitude low frequency earthquakes beneath the inner wall of the Japan trench. These low frequency events were found to have shallow focal depths, which Fukao and Kanjo (1980) interpreted as being consistent with the subduction of the oceanic plate. The occurrence of 
low frequency or low-stress-drop events toward the trench reflects the lesser degree of mechanical coupling between the subducting and overriding plates. The patterns observed in the southern Kurile and Japan trench suggest that the shallow parts of the lithospheric boundary are more weakly coupled than the deeper parts.

\section{Impulsive events}

In contrast to the four low-stress-drop earthquakes, the remaining $M_{\mathrm{s}} \geqq 7.0$ events occurring in the southern Kurile Islands have impulsive $\mathbf{P}$ wave seismograms indicating short source process times. Figure 13 contrasts three of these relatively simple waveforms and source time functions with $P$ wave seismograms and source time functions from the neighboring low-stress-drop earthquakes. Figure 14 shows the $\mathrm{P}$ waveforms for all of the impulsive events recorded at stations at similar azimuths and distances. Most of the seismograms consist of relatively simple waveforms. To further understand the nature of the impulsive earthquakes, we examined their spatial distribution. We do this by studying the seismicity in the source regions of each great earthquake separately.

\subsection{The 1958 and 1963 source regions}

Figure 15 shows the epicenters of the impulsive events occurring within the source regions of the 1958 Etorofu and the 1963 Kurile Islands earthquakes. The impulsive events cluster in two regions, in the northeastern and southwestern portions of the 1958 aftershock area (Fig. 15). The northeast portion ruptured in a foreshock one day before the great 1963 event. This same region ruptured again with a magnitude $\approx 7$ earthquake on January 21, 1976. Source time functions averaged from several stations for both these events are shown in Fig. 16. The source functions are very similar and have an impulsive nature. The aftershock areas of both of these events extend significantly into the aftershock areas of the June 11, 1965 and October 20, 1963 low-stress-drop events (Fig. 17). We believe that these two earthquakes represent the failure of a localized strong

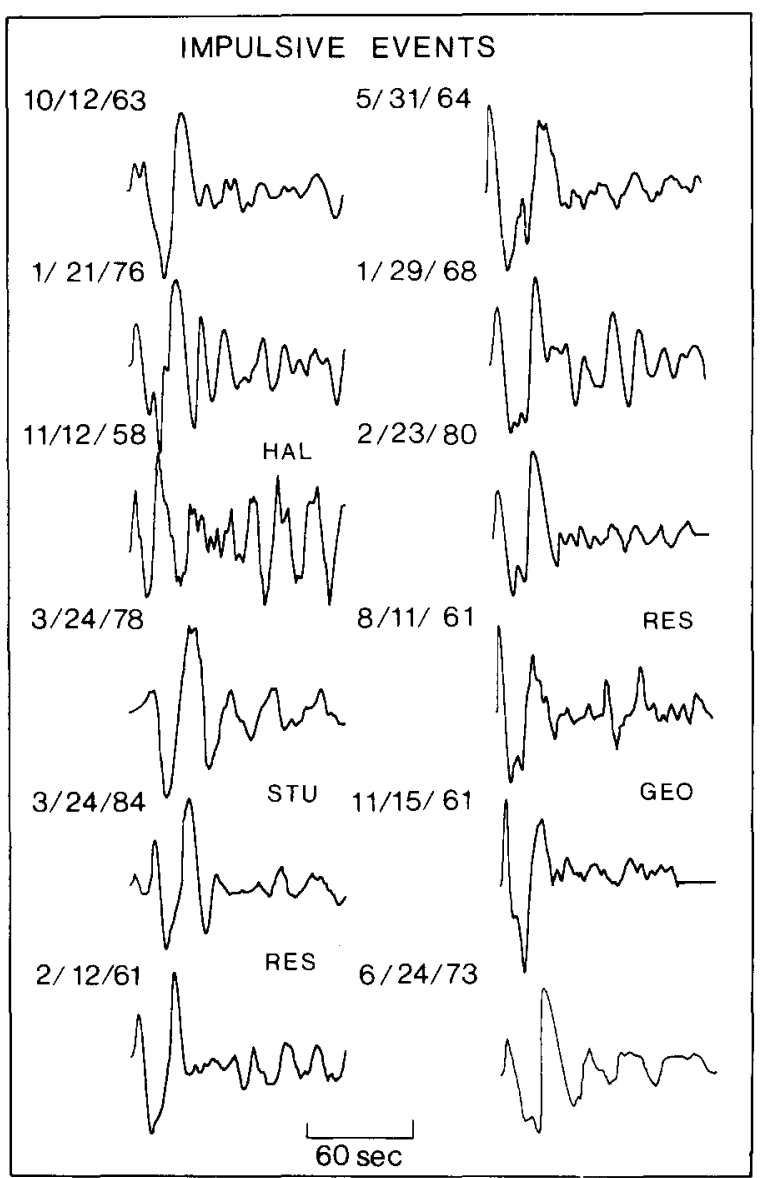

Fig. 14. P wave seismograms recorded at IST (or listed station) for 12 of the impulsive earthquakes. Note the similarity in the waveforms from adjacent events $(5 / 31 / 64,1 / 29 / 68$, and $2 / 23 / 80$ ).

region (a small asperity) in the epicentral region of the 1963 and 1976 events. The large aftershock areas for these two events probably indicate the migration of stress into the weak regions ruptured by the 1965 and 1963 events.

The southwestern portion of the 1958 aftershock area experienced an abundance of seismic activity from 1946 to 1978 . The largest event in this region occurred on March 24, 1978. This magnitude 7.6 event was preceded by unusually high foreshock activity. At least five of its precursor events had magnitudes larger than 6.0 , with a magnitude 7.5 event occurring 1 day before on March 23, 1978. The exact location of the event of March 23 is 


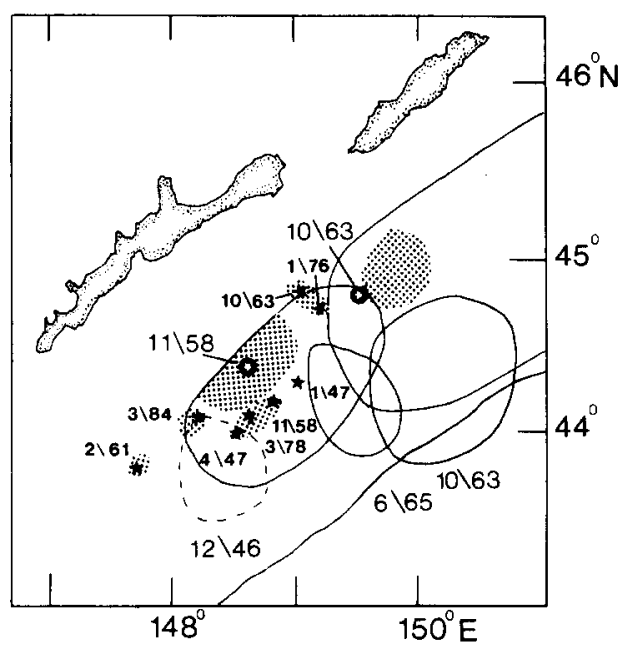

Fig. 15. Seismicity in the source areas of the 1958 Etorofu and 1969 Kurile Islands earthquakes. The open stars are the mainshock epicenters, the solid stars are the epicenters of the impulsive events that occur in this region. The dominant (mainshock) and secondary asperity areas are stippled and the aftershock areas of three low-stress-drop events are indicated with solid lines where well determined and dashed lines where more speculative.

very poorly known due to the occurrence of a large foreshock one minute before it. Its most probable location according to J. Regan and $\mathrm{H}$. Kanamori (unpublished manuscript, 1980), is $<50$ $\mathrm{km}$ east of the March 24 event. The body waves of the March 23 event were obscured by the foreshock, so its source process could not be investigated. Long-period $\mathrm{P}$ waves from 18 azimuthally well-distributed WWSSN stations recording the March 24 event were deconvolved using the focal mechanism of Regan and Kanamori (1980) and a source depth of $0-30 \mathrm{~km}$. The source time functions consist of one main asymmetric pulse of moment release which has a longer rise time than fall off (Fig. 16). The timing of the termination of this pulse varies azimuthally; the directivity indicates a northeasterly rupture of $<70 \mathrm{~km}$ from the epicenter. The aftershocks of the March 24, 1978 event extend significantly into the aftershock areas of both the 1965 and 1963 low-stress-drop events (Fig. 17). The average seismic moment obtained from the body waves is $5.5 \times 10^{27} \mathrm{dyn} \mathrm{cm}$ (excluding the nodal and diffracted stations), a value about twice as large as the surface wave

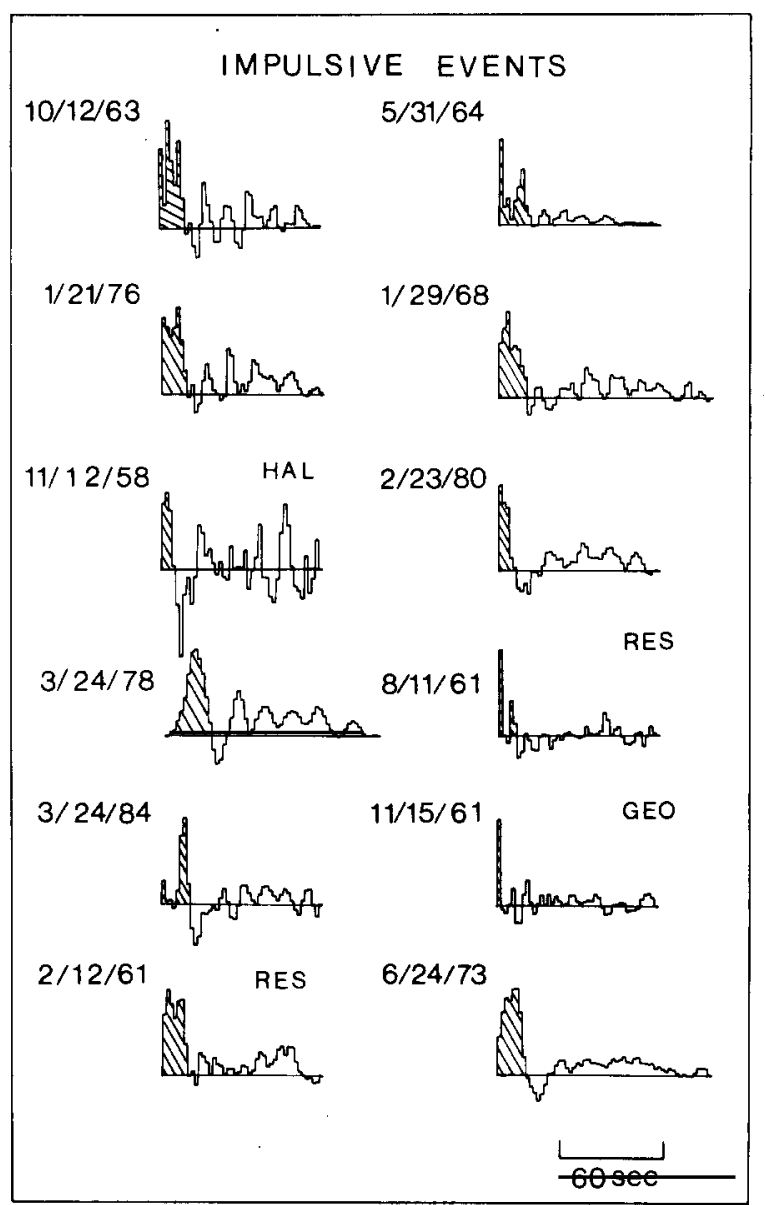

Fig. 16. Deconvolved source time functions averaged from several stations (except where station names are indicated) for 12 of the impulsive events.

moment reported by Regan and Kanamori (1980). The March 24, 1978 and most probably the March 23, 1978 events represent the rupture of small asperities in the epicentral region of the 1978 events (Fig. 15).

The largest aftershock $\left(M_{\mathrm{s}}=7.2\right)$ of the 1958 Etorofu earthquake occurred on November 12, 1958. Its epicenter is very close to the epicenter of the March 24, 1978 event (Fig. 15). The source time function deconvolved from the $\mathrm{P}$ wave recorded at Halifax is shown in Fig. 16. It consists of one main pulse of moment release and probably corresponds to failure of the same small asperities, albeit with much smaller displacement than the 1978 events. This portion of the 1958 


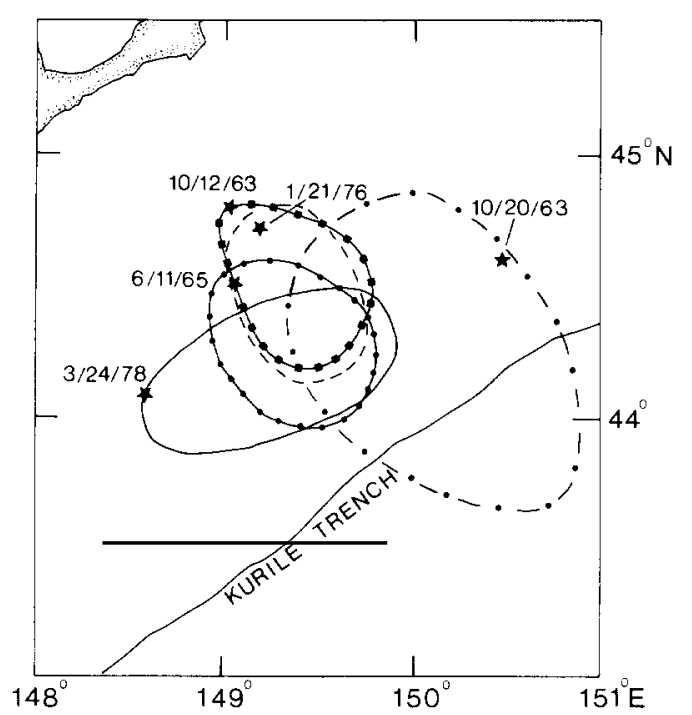

Fig. 17. One week aftershock areas of the low-stress-drop and impulsive earthquakes occurring in the source regions of the 1958 Etorofu and 1963 Kurile Islands earthquakes. The stars indicate the epicenters of these events. Different patterns represent the aftershock areas of the $3 / 24 / 78$ event (solid line), the $6 / 11 / 65$ event (solid line with circles), the 10/12/63 event (solid line with boxes), the $1 / 21 / 76$ event (dashed line) and the $10 / 20 / 63$ event (dashed line with circles).

aftershock area experienced three magnitude 7-7.2 events between December 1946 and April 1947 (Fig. 15). We have already discussed the possible low-stress-drop nature of the December 1946 event and have dashed in a rather speculative aftershock area in Fig. 15. The 1947 events cluster around the small asperities located in this portion of the fault zone. The locations of these events are very poorly known and we suspect that their occurrence also represents the failure of the same small asperities that failed during the 1978 events and the 1958 aftershock. Although we cannot determine the size of the secondary asperities from body wave directivity, the impulsiveness of the events rupturing them implies small dimensions; we illustrate this schematically by shading only the epicentral regions.

\subsection{The 1969 source region}

Six impulsive earthquakes occurred in the aftershock area of the 1969 Kurile Islands earth- quake. Their spatial distribution indicates a clustering into two groups at the down-dip edge of the 1969 aftershock area, one northeast and the other southwest of the main shock asperity (Fig. 18). The aftershock areas of many of these events extend toward the trench and overlap significantly with the aftershock areas of the two low-stressdrop earthquakes (Fig. 19). Shimazaki (1975) considered the 1968 Shikotan-Oki earthquake $(1 / 29 / 68)$ to be a low-stress-drop event because its aftershock area $\left(\approx 4000 \mathrm{~km}^{2}\right)$ is twice as large as the fault area expected from the calculated seismic moment $\left(1.0 \times 10^{27} \mathrm{dyn} \mathrm{cm}\right)$. Schwartz and Ruff (1985) applied the same reasoning to infer that the $2 / 12 / 61$ event was also a low-stress-drop earthquake. We now reinterpret these events as breaking highly stressed regions (secondary asperities) producing impulsive time functions (Fig. 16). Their large aftershock areas are probably caused by the migration of the rupture into the trenchward weak regions. The large distance between the $2 / 12 / 61$ and $3 / 24 / 84$ events may indicate the presence of two secondary asperities in the northeast corner of the 1969 aftershock area. Owing to the large uncertainty in the location of the

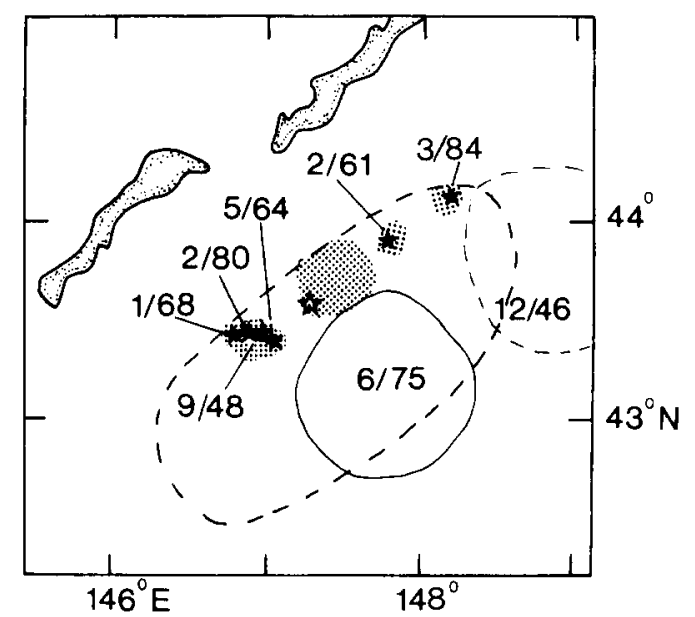

Fig. 18. Seismicity in the source area of the 1969 Kurile Islands earthquake. The open star is the mainshock epicenter and the solid stars are the epicenters of the impulsive events that occur in this region. The dominant and secondary asperity areas are stippled and the aftershock areas of the low-stress-drop events are indicated with solid lines where well determined and dashed lines where more speculative. 


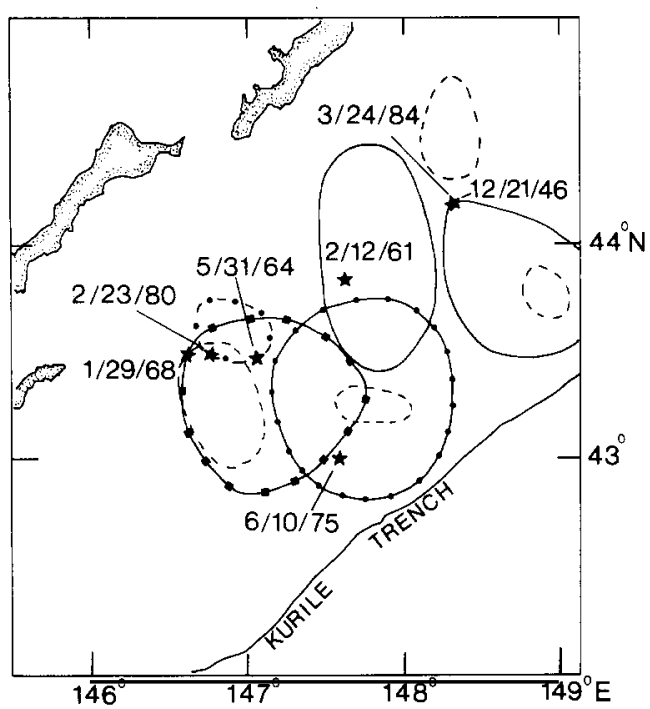

Fig. 19. One week aftershock areas of the low-stress-drop and impulsive earthquakes occurring in the source region of the 1969 Kurile Islands earthquake. The stars indicate the epicenters of these events. Different patterns represent the aftershock areas of the $1 / 29 / 68$ event (solid line with boxes), the $2 / 23 / 80$ event (dashed line), the $5 / 31 / 64$ event (dashed line with circles), the $6 / 10 / 75$ event (solid line with circles), the $2 / 12 / 61$ event (solid line), the $12 / 21 / 46$ event (solid line) and the $3 / 24 / 84$ event (dashed line).

$2 / 12 / 61$ event, it is also possible that both events broke the same small asperity located near the epicenter of the $3 / 24 / 84$ event.

\subsection{The 1973 source region}

The last three $M_{\mathrm{s}} \geqq 7.0$ earthquakes in the southern Kurile Islands arc occurred in the aftershock area of the 1973 Nemuro-Oki earthquake (Fig. 20). Their epicenters are again located at the down-dip edge of the 1973 aftershock area. For the two 1961 events, only one record was obtained for each. The $8 / 11 / 61$ event was recorded at Resolute Bay and the $11 / 15 / 61$ event at Georgetown. Instrument responses are well known at both stations. The third event occurred on June 24, 1973 as the largest aftershock of the 1973 Nemuro-Oki earthquake. Based on the short duration of the source functions of these events (Fig. 16 ), we classify them as impulsive earthquakes

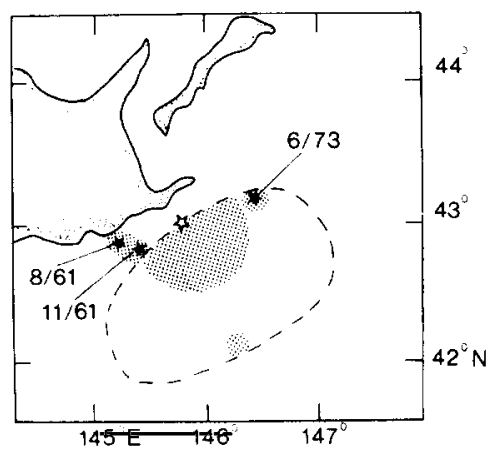

Fig. 20. Seismicity in the source area of the 1973 Nemuro-Oki earthquake. The open star is the mainshock epicenter and the solid stars are the epicenters of the impulsive events that occur in this region. The dominant and secondary asperity areas are stippled.

rupturing two small asperities that lie on either side of the large mainshock asperity.

\section{Discussion and conclusions}

We have investigated all $M_{s} \geqq 7.0$ earthquakes that have occurred in the southern Kurile Islands trench since 1946 and found at first glance a complicated seismicity pattern. However, the seismic behavior in this region can be understood in terms of a simple pattern of fault plane heterogeneity. Though a hierarchy of mechanical strengths and scale lengths of heterogeneity undoubtedly exists on the lithospheric interface, we can idealize it as two scales of asperities. The strongest regions or dominant asperities are on the order of $50-100 \mathrm{~km}$ and they ruptured in the four largest earthquakes. Detailed body wave studies of their source processes allowed these asperities to be approximately located on the fault plane. Many large events occur in the area between dominant asperities. The source regions of these large events do not substantially overlap the mainshock asperities. These events occur in two modes: (1) as impulsive events that rupture secondary, smaller asperities $<50 \mathrm{~km}$, with a shorter recurrence interval than for the main asperities, or (2) as lowstress-drop events that rupture extensive, relatively weak regions. The resulting picture (Fig. 21a) is a 

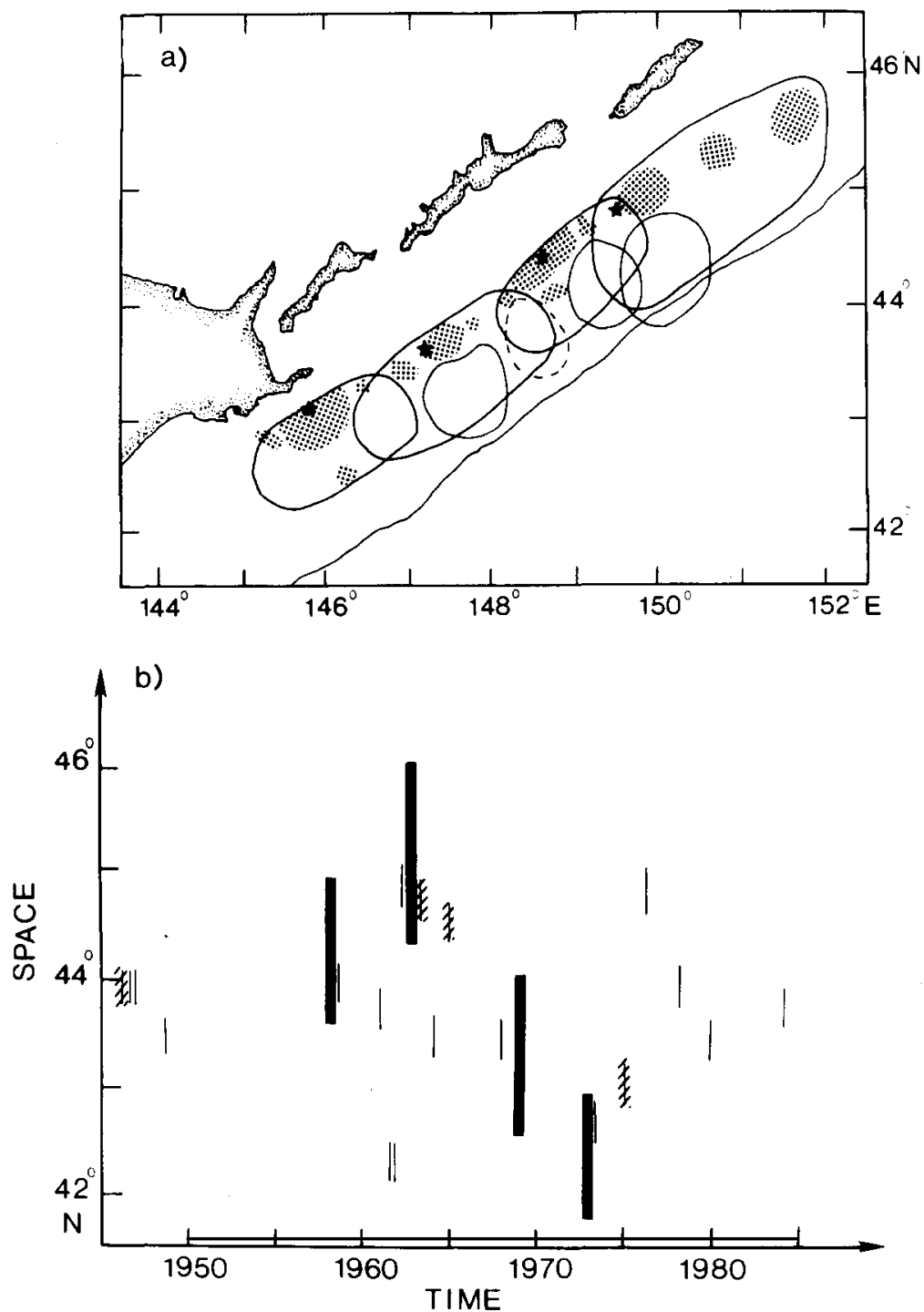

Fig. 21. (a) Map of the fault plane heterogeneity in the southern Kurile Islands arc. The stippled areas represent the regions of enhanced strength; they are of two scale lengths. The largest asperities ruptured in the great earthquakes and the secondary asperities ruptured in the large impulsive events. A weak seismic coupling trenchward of the mainshock epicenters is indicated by the occurrence of low-stress-drop events (aftershock areas are shown by solid or dashed ovals). (b) Space-time plot of the $M_{s} \geqslant 7$ seismicity in the southern Kurile Islands arc since 1946. The rupture extent of the four largest earthquakes is indicated by the heavy bars, the low-stress-drop events by the hachured bars and the impulsive events by the remaining solid bars.

map of the fault plane heterogeneity in the southern Kurile Islands arc. We make the following observations:

(1) the moment release associated with the mainshock ruptures is concentrated in localized regions of the aftershock areas (asperities) that are surrounded by extensive weak regions. Slip occurs in the weak regions during the great earthquakes, but the amount of slip is less than at the asperities;

(2) the aftershock areas of the four largest events abut against adjacent earthquake asperities 
suggesting that the mainshock ruptures terminate at asperities that are not ready to slip;

(3) most of the secondary asperities are located adjacent to the mainshock asperities at the downdip edge of the aftershock areas forming a nearcontinuous zone of asperities. This segregation between the strong and weak regions indicates that the down-dip portion of the lithospheric interface is a strongly coupled zone, which fails impulsively in large or great earthquakes. The trenchward segment appears to be more weakly coupled, and slips both coseismically with the asperity rupturing earthquakes that occur further down-dip, and alone as low-stress-drop events; and

(4) inclusion of the moment released in the numerous $M_{\mathrm{s}} \geqq 7$ events in a calculation of seismic slip rates in the southern Kurile Islands arc increases this estimate from previous values of onethird to one-half to two-thirds of the plate convergence rate (Kanamori, 1977). Excluding the four largest earthquakes in this region, the remaining accumulated moment in the last 40 years amounts to the equivalent of the occurrence of another $M_{\mathrm{w}}=8.0$ great earthquake. In regions that experience frequent $M_{\mathrm{s}} \geqq 7$ earthquakes, like the southern Kurile Islands arc, these events do contribute significantly to the total moment accumulation and their study is important for understanding the systematics of the subduction process in these regions.

Finally, the spatio-temporal pattern of the great and large earthquakes in the southern Kurile Islands arc may have strong implications for earthquake prediction. The seismic gap hypothesis has made long-term earthquake forecasting possible. This theory has been successful at predicting the rupture of the dominant asperities on a time scale of about 20-100 years. The challenge now lies in forecasting plate boundary earthquakes on a shorter time scale. The nature of the precursory behavior in subduction zones reflects the state of stress in the epicentral region and is therefore important to intermediate-term earthquake prediction. Each of the four great earthquakes that occurred in the southern Kurile Islands trench was preceded by at least one large event from 12 years to 1 day before the main event. Figure $20 \mathrm{~b}$ is a schematic space-time plot of events with $M_{\mathrm{s}} \geqq 7.0$ in the southern Kurile Islands trench since 1946. The large, heavy bars represent the four great earthquakes and the hachured bars represent the four low-stress-drop events. The remaining bars are the large impulsive earthquakes. Two such events in 1947 preceded the 1958 Etorofu earthquake, one event occurred one day before the 1963 Kurile Islands earthquake, four events in 1948, 1961, 1964 and 1968 preceded the 1969 Kurile Islands earthquake, and two events in 1961 preceded the 1973 Nemuro-Oki earthquake. These events ruptured secondary asperities adjacent to the mainshock asperities, and consequently produced stress concentrations at the main asperities. Secondary asperities rupture much more frequently than the dominant asperities. Failure of each of the secondary asperities contributes to the loading of the adjacent mainshock asperity, but it may take multiple failures of the secondary asperities for the stress at the dominant asperity to reach its yield strength. Large earthquakes have occurred after the great earthquakes and may represent the beginning of a cycle of failure on secondary asperities that will terminate with a great earthquake. Unfortunately, we do not know exactly how many smaller events will happen before the dominant asperity is ready to rupture. Perhaps a more detailed analysis will show some differences in the $M_{\mathrm{s}} \geqq 7$ events. In any case, a viable intermediate-term prediction scheme in this region would necessitate the integration of the concept of seismic gaps with the monitoring of the large precursory earthquakes in a mature seismic gap.

\section{Acknowledgments}

We thank Lamont-Doherty Geological Observatory for the frequent use of their historical seismogram and film chip libraries. We are grateful to Holly Eissler and Paul Roberts for supplying the records and instrument characteristics from the Caltech stations. We also thank Susan Beck for the results of the 1963 Kurile Islands earthquakes prior to publication and for many helpful suggestions. We appreciate the constructive com- 
ments and aid in data collection and processing rendered by Thorne Lay, Chris Lynnes, Chris Young, Doug Christensen and Melissa Schell throughout the course of this project. This research was supported by grants to L.J.R. from the National Science Foundation (EAR8351515 and EAR8407786) and the Shell Companies Foundation. S.Y.S. is grateful to the American Geophysical Union for making travel funds available to present this research at the 1985 IASPEI meeting in Japan.

\section{References}

Abe, K., 1973. Tsunami and mechanism of great earthquakes. Phys. Earth Planet. Inter., 7: 143-153.

Abe, K., 1981. Physical size of tsunamigenic earthquakes of the northwestern Pacific. Phys. Earth. Planet. Inter., 27: 194-205.

Beck, S.L. and Ruff, L.J., 1984. The rupture process of the great 1979 Colombia earthquake: evidence for the asperity model, J. Geophys. Res., 89: 9281-9291.

Beck, S.L. and Ruff, L.J., 1985. The rupture process of the 1976 Mindanao earthquake. J. Geophys. Res., 90: 6773-6782.

Beck, S.L. and Ruff, L.J., 1987. Source process of the 1963 Kurile Islands earthquake, J. Geophys. Res., in press.

Bolduc, P.M., Ellis, R.M. and Russell, R.D., 1972. Determination of the seismograph phase response from the amplitude response. Bull. Seismol. Soc. Am., 62: 1665-1672.

Bullen, K.E., 1963. An Introduction to the Theory of Seismology. Cambridge University Press, Cambridge, 381 pp.

Christensen, D.H. and Ruff, L.J., 1985. Analysis of the trade-off between hypocentral depth and source time function. Bull. Seismol. Soc. Am., 75: 1637-1656.

Fedotov, S.A., 1965. Regularities of the distribution of strong earthquakes in Kamchatka, the Kurile Islands, and northeast Japan. Trudy Inst. Fiz. Acad. Nauk. SSSR, 36: 66.

Fukao, Y., 1979. Tsunami earthquakes and subduction process near deep-sea trenches. J. Geophys. Res., 84: 2303-2313.

Fukao, Y. and Furumoto, M., 1979. Stress drops, wave spectra and recurrence intervals of great earthquakes-implications of the Etorofu earthquake of 1958 November 6. Geophys. J.R. Astron. Soc., 57: 23-40.

Fukao, Y. and Kanjo, K., 1980. A zone of low-frequency earthquakes beneath the inner wall of the Japan Trench. Tectonophysics, 67: 153-162.

Furumoto, M., 1979. Initial phase analysis of $R$ waves from great earthquakes. J. Geophys. Res., 84: 6867-6874.

Hagiwara, T., 1958. A note on the theory of the electromagnetic seismograph. Bull. Earthquake Res. Inst. Tokyo Univ., 36: $139-164$.

Hatori, T., 1982. Wave magnitudes of the Kurile-Kamchatka tsunamis-tsunami effect in Japan. Bull. Earthquake Res. Inst. Tokyo Univ., 57: 687-699.
Hodgson, J., 1958. Seismological bulletin, Dominion Observ., Dep. of Mines and Tech. Surv., Ottawa, Canada, January-March 1958, 94 pp.

Jarrard, R.D., 1986. Relations among subduction parameters. Rev. Geophys., 24: 217-284.

Kanamori, H., 1970. Synthesis of long-period surface waves and its application to earthquake source studies-Kurile Islands earthquake of October 13, 1963. J. Geophys. Res., 75: 5011-5027.

Kanamori, H., 1972. Mechanism of tsunami earthquakes. Phys. Earth Planet. Inter., 6: 346-359.

Kanamori, H., 1977. Seismic and aseismic slip along subduction zones and their implications. In: P.M. Talwani and W.C. Pittman (Editors), Island Arcs, Deep Sea Trenches and Back-Arc Basins, Am. Geophys. Union, Washington DC, pp. 163-174.

Kanamori, H., 1981. The nature of seismicity patterns before major earthquakes. In : D.W. Simpson and P.G. Richards (Editors), Earthquake Prediction, an International Review, pp. 1-19.

Kanamori, H. and Anderson, D.L., 1975. Theoretical basis of some empirical relationships in seismology. Bull. Seismol. Soc. Am., 65: 1073-1095.

Kelleher, J., Sykes, L.R. and Oliver, J., 1973. Possible criteria for predicting earthquake locations and their applications to major plate boundaries of the Pacific and the Caribbean. J. Geophys. Res., 78: 2547-2585.

Kelleher, J., Savino, J., Rowlett, H. and McCann, W., 1974. Why and where great thrust earthquakes occur along island arcs. J. Geophys. Res., 79: 4889-4899.

Kikuchi, M. and Fukao, Y., 1987. Inversion of long-period P waves from great earthquakes along subduction zones. Tectonophysics, submitted.

Lay, T. and Kanamori, H., 1980. Earthquake doublets in the Solomon Islands. Phys. Earth Planet. Inter., 21: 283-304.

Lay, T., Kanamori, H. and Ruff, L., 1982. The asperity model and the nature of large subduction zone earthquakes. Earthquake Pred. Res., 1: 3-71.

Miller, H.J., 1963. Calibration of long-period seismographs at thirteen stations throughout the world. Advanced Research Projects Agency Vela Uniform, Scientific Report No. 24. 54 pp.

Mogi, K., 1968. Some features of recent seismic activity in and near Japan. Bull. Earthquake Res. Inst., Tokyo Univ., 46: 1225.

Nakanishi, I. and Kanamori, H., 1984. Source mechanisms of twenty-six large shallow earthquakes ( $M_{\mathrm{s}} \geqq 6.5$ ) during 1980 from P-wave first motions and long-period Rayleigh wave data. Bull. Seismol. Soc. Am., 74: 805-818.

Peterson, E.T. and Seno, T., 1984. Factors affecting seismic moment release rates in subduction zones. J. Geophys. Res., 89: 10233-10248.

Regan, J. and Kanamori, H., 1980. A complex earthquake sequence in the Kurile Islands (March 23, 24, 1978): its implications on the behavior of seismic gaps. Trans. Am. Geophys. Union, EOS, 61: 1026.

Ruff, L. and Kanamori, H., 1980. Seismicity and the subduction process. Phys. Earth Planet. Inter., 23: 240-252. 
Ruff, L. and Kanamori, H., 1983. The rupture process and asperity distribution of three great earthquakes from longperiod diffracted P-waves. Phys. Earth Planet. Inter., 31: $202-230$.

Ruff, L.J., 1984. Tomographic imaging of the earthquake rupture process. Geophys. Res. Lett., 11: 629-632.

Schwartz, S.Y. and Ruff, L.J., 1985. The 1968 Tokachi-Oki and the 1969 Kurile Islands earthquakes: Variability in the rupture process. J. Geophys. Res., 90: 8613-8626.

Shimazaki, K., 1974. Nemuro-Oki earthquake of June 17 1973: A lithospheric rebound at the upper half of the interface. Phys. Earth Planet. Inter., 9: 314-327.

Shimazaki, K., 1975. Low-stress-drop precursor to the Kurile Islands earthquake of August 11, 1969. Trans. Am. Geophys. Union, EOS, 56: 1028.

Shimazaki, K. and Geller, R.J., 1977. Source process of the Kurile Islands tsunami earthquake of June 10, 1975. Trans. Am. Geophys. Union, EOS, 58: 446.
Sykes, L.R., 1971. Aftershock zones of great earthquakes, seismicity gaps, and earthquake prediction for Alaska and the Aleutians. J. Geophys. Res., 76: 8021-8041.

Takemura, M., Koyama, J. and Suzuki, Z., 1977. Source process of the 1974 and 1975 earthquakes in Kurile Islands in special relation to the difference in excitation of tsunami. Sci. Rep. Tohoku Univ. Ser. 5, 24: 113-132.

Uyeda, S. and Kanamori, H., 1979. Back-arc opening and the mode of subduction. J. Geophys. Res., 84: 1049-1061.

Utsu, T., 1980. Spatial and temporal distribution of lowfrequency earthquakes in Japan. J. Phys. Earth, 28: 361-384.

Veith, K.F., 1974, The Relationship of Island Arc Seismicity to Plate Tectonics. Ph.D. Thesis, University of Minnesota, 69 pp.

Wadati, K., 1928. Unusual nature of deep sea earthquakes-on the three types of earthquakes, Kishoshushi. J. Meteorol. Soc. Jpn. Ser. 2, 6: 1-43 (in Japanese). 